\title{
CHOICE ARCHITECTURE FOR ARCHITECTURE CHOICES: EVALUATING SOCIAL HOUSING INITIATIVES PUTTING TOGETHER A PARSIMONIOUS AHP METHODOLOGY AND THE CHOQUET INTEGRAL
}

Francesca Abastante ${ }^{1}$, Salvatore Corrente ${ }^{2}$, Salvatore Greco ${ }^{2,3}$, Alessio Ishizaka ${ }^{3}$, Isabella M. Lami ${ }^{1}$

${ }^{1}$ Department of Regional and Urban Studies and Planning (DIST), Politecnico of Torino, Viale Mattioli 39, 10125 Turin, Italy.

${ }^{2}$ Department of Economics and Business, University of Catania, Corso Italia 55, 95129, Catania, Italy.

${ }^{3}$ University of Portsmouth, Portsmouth Business School, Centre of Operations Research and Logistics (CORL), Richmond Building, Portland Street, Portsmouth.

Email addresses: francesca.abastante@polito.it (F. Abastante), salvatore.corrente@unict.it (S. Corrente), salgreco@unict.it (S. Greco), Alessio.Ishizaka@port.ac.uk (A. Ishizaka), isabella.lami@polito.it (I.M. Lami)

\begin{abstract}
Choice architecture concerns different forms and procedures to present and handle a decision problem. It is a paradigm around which many theoretical results have been collected within behavioural psychology and experimental economics and many successful applications have been implemented in the domains of health, finance and social choices. In this work, we propose an application of the basic idea of architecture choice that is designing decision support procedures for complex problems, with a focus on housing realm. We consider a real-world problem in which 21 Social Housing initiatives sited in the Piedmont region (Italy) had to be evaluated taking into account several criteria and, to this aim, we propose a decision analysis methodology for supporting assessment in such complex problems. Our main preoccupations in designing the decision aiding procedure were related to build a model that, on one hand, permits to take into consideration the many delicate points of the problem, while, on the other hand, requires to the Decision Maker (DM) an affordable cognitive burden in terms of preference elicitation and interpretation of the obtained results. Since synergy and redundancy of criteria constitute important aspects of the decision problem, we aggregated evaluations on considered criteria by means of the Choquet integral. To maintain the preference information asked to the DM simple and not too requiring, we put together a recently proposed parsimonious approach of the Analytical Hierarchy Process (AHP) and the Non-Additive Robust Ordinal Regression (NAROR). The Parsimonious AHP permitted to assign a value on a common scale to the performances of all criteria, while the NAROR permitted to elicit the importance and the interaction of criteria taking into account all the possible values for the preference parameters compatible with the preference information supplied by the DM. Our methodology allowed a fruitful interaction with the DM that had the possibility to update the preference information during the decision process until he/she felt convinced and satisfied of the obtained result. The suitability and the interest of the proposed methodology were confirmed by the subjective final appreciation of the DM as well as by the objective absence of specific
\end{abstract}


inconsistencies in the AHP procedure and in the non-additive robust ordinal regression, which witnessed the beneficial contribution of our approach.

Keywords: Choice architecture, Analytic Hierarchy Process, Parsimonious preference information, Social Housing, Choquet Integral, Robust Ordinal Regression

\section{Introduction}

In an increasingly complex world, decisions become more and more intricate, problematic and troublesome. Several points of view have necessarily to be taken into consideration, so a good decision support needs a rich and fruitful interaction with the Decision Maker (DM). Hence, particular attention has to be paid on reducing the cognitive burden and the possible biases (Miller 1956, Hammond et al. 1999, Milkman et al. 2009) when collecting preference information from the DM. These remarks are assuming special importance for architecture problems, which are characterised by heterogeneous social, economic, environmental and cultural domains having consequences on both the territory and the society. Here comes the necessity for new decision support methods able to structure, process and aggregate the information collected and provided by the DM, in a simple and understandable way, avoiding misunderstanding during the decision process and beyond. To define this new general decision processes perspective, we can "borrow" a very well-known expression from the economists: choice architecture (Thaler and Sunstein 2008). Moreover, since this concept is here applied to the architecture problems domain, a "word pun" is easy: choice architecture for architecture choices.

In this paper, we apply the idea of choice architecture for architecture choices to one of the most urgent needs directly related to the social dimension of the economic global crisis, which is the new housing demand from the so-called in "work-poverty population" (Dartford Borough Council 2011, Marx and Nolan 2012). This particular social target is composed by subjects in a situation of housing vulnerability or who need transitory housing solutions and constitutes a "grey zone" for the social housing policies. This new type of demand has emerged all over Europe and has increased dramatically in the last 20 years (CECODHAS - Housing Europe, housingeurope.com). In this sense, the beneficiaries of the Social Housing ( $\mathrm{SH}$ ) encompass people not having the minimum income needed to pay a rent on the regular real-estate market and people needing social support (Marx and Nolan 2012).

This new growing housing demand is characterized by high economic and social fragility (Wills and Linneker 2014). The rebalancing of the relationship between the number of households and the 
number of inhabitants is not dealt with but rather an attempt is made to lessen the gap between access to the housing market and the real disposable budget income of the households. It is also expected that the size that this phenomenon has reached in recent years will show no sign of decline in the medium-long term in many European Countries, and it will probably cause a severe crisis in the welfare system and in the real estate market (ec.europa.eu).

Despite real estate investments being closely linked to the urban, regulatory and economic contexts in which they are applied, it is possible to recognise synergies and shared features in defining elements of this housing crisis across the European Union (EU) member states, namely:

- the desire and need to provide affordable housing through the construction and lease of homes (Crook and Kemp 2014, Whitehead et al. 2012, Oxley 2012, Haffner and Heylen 2011);

- the definition of target groups either in socio-economic terms or in relation to other kinds of vulnerability;

- the pursuit of housing quality by achieving energy efficiency standards and reducing social exclusion (Czischke and Pittini 2007).

After the Second World War, SH evolved gradually from centralized control to decentralized management style, engaging private sector involvement (Wong and Goldblum 2016). Moreover, while after the Second World War the focal point of the SH was to provide houses to people in an emergency situation, over the last 20 years the human factor has become fundamental: the $\mathrm{SH}$ focus has shifted from the building to the people living in the building (CECODHAS Housing Europe, housingeurope.com). This evolution of the SH concept needs for new polices able to overcome the traditional SH logic, activating new decision process and procedures able to find effective means of investment for the institutions that operate in this field (not only the public sector but also the third sector) (Lami and Abastante 2017).

The first author of this paper experienced several $\mathrm{SH}$ decision processes working in the private sector with the Programma Housing (PH), which is an operating entity of the Italian Bank Foundation "Compagnia di San Paolo" (CSP - Turin, Italy). The PH is composed by experts in different fields (i.e. architects, engineers, evaluators, psychologists and sociologists) with the aim of giving grant contributions to third bodies submitting innovative $\mathrm{SH}$ projects $(9.000 .000$ euro have been given in the period 2007 - 2018). In this sense, the PH has to assess a number of SH projects every year in order to properly finance the most interesting ones acting as a Decision Maker (DM) for the aforementioned processes.

Thanks to this connection between the authors and the $\mathrm{PH}$, we had the opportunity to face a real SH decision process. To this aim, we propose and test a new Multicriteria Decision Analysis (MCDA) procedure able to support complex decision processes to increase the transparency and quality of the processes of allocating public and private resources taking into account the concept of Choice Architecture (Thaler and Sunstein 2008). Observing that people adopt different strategies in a decision process depending on the size and complexity of the available options, Thaler and Sunstein (2008) affirm that a good choice architecture, i.e. the design of the environment in which people make choices, will provide the structure, and the structure will affect outcomes.

This seems particularly important in SH realm: scholars have viewed that SH needs to be informed by increasingly sophisticated conceptions that treat the setting as a complex, multidimensional field (Camoletto et al. 2017, Allen et al. 2008, Wills and Linneker 2014). This is the realm, where the concepts get fuzzier, therefore requiring the use of a richer theory and more complex Methods, that, 
however, permit to interact with the DM with the simplest and most understandable possible procedures. Multifaceted social, economic and financial balance, environmental issues and quality of life make it an intriguing topic that characterizes the field. It is important to underline that the aim of the SH programs at a EU level is increasingly not simply to meet housing needs (such as rental housing at rents agreed), but to promote social inclusion and to improve the living conditions of people from a sustainable social, environmental, institutional, economic and financial point of view.

An adequate choice architecture could help to rethink the whole system of SH in order to create languages, tools and parameters able to develop, compare and evaluate SH projects focusing on the public and private interests. In addition, one of the main difficulties in this context is the need to engage with different types of collective actions, the plurality of subjects with different aims and resources and the lack of homogeneous information. Addressing these difficulties can be extremely challenging (Lami 2019). In the light of this, the paper addresses the issue of evaluating and ranking $\mathrm{SH}$ projects proposing a new methodological approach that allows to tackle decision problems characterised by: i) high number of alternatives to rank; ii) qualitative and quantitative criteria which could violate the preference independence; iii) the possibility for the DM to express her preferences only on the alternatives she knows best.

According to the literature, as the MCDA procedures are countless, it is necessary to deeply reflect on the most suitable method for the decision context in exam (Roy and Slowinski 2013, Abastante 2016). In fact, failure to identify the real nature of the decision problem could lead to the application of the wrong methodology placing the resulting analysis at risk and greatly diminishing the relevance of the outputs (Munda 2008; Salgado et al. 2009).

Thus, we imagined an approach permitting to organize the information by alternating stages of dialogue with the DM and calculation. The dialogue stages aim to collect information directly from the DM, which can reveal his preferences about the alternatives and the criteria at stake. The DM preferences are in turn taken into account in the calculation stages.

After a deep reflection, the proposed methodological approach is based on the conjoint application of the Parsimonious AHP (Abastante et al. 2018), an extension of the Analytic Hierarchy Process (AHP) (Saaty and Ozdemir 2003, Saaty 1980), together with the Choquet integral (Choquet 1953) and the Non-Additive Robust Ordinal Regression (NAROR; Angilella et al. 2010a).

Combining the parsimonious AHP and the NAROR, we apply a novel methodology in order to take into account the following main concerns, basilar for all MCDA procedures:

- collection of preference information from the DM in an easy and understandable way: this is the case of both the preference information required by AHP and NAROR;

- consideration of complex aspects of the decision problems (in our case, interaction between criteria) but taking the whole methodology as simple as possible: indeed, in NAROR we consider a 2-additive Choquet integral (Grabisch 1997) that considers only interactions between pairs of criteria, so that the whole aggregation procedure can be seen as a "minimal" extension of the usual "weighted sum".

The structure of the paper is the following: section 2 synthetically illustrates the theoretical aspects of the methodology; section 3 clarifies how to apply it to a case study detailed in each step; mention has to be made to the fact that this is the first application of the new methodology to a real decision problem. The valuation process and the results are further discussed in section 4, while conclusions are drawn in section 5 . 


\section{Methodological framework}

In this section we give a synthetic description of the concept of Choice Architecture. Moreover, we provide here an exhaustive description of the two basic components of the proposed methodological approach (Abastante et al. 2018) that are, Analytic Hierarchy Process (AHP) and Choquet integral within Robust Ordinal Regression (ROR).

\subsection{The concept of Choice Architecture}

The idea of Choice Architecture has been proposed by the Nobel prize Richard Thaler, together with Cass Sunstein, in their book Nudge: Improving Decisions About Health, Wealth, and Happiness (2008). On the basis of the evidence supplied by large volume of research in behavioural psychology and experimental economics, choice architecture proposes to get better decisions by appropriately shaping the decision problem. As synthesised by Munscher et al. (2016), "Choice architecture emerged when researchers began to take an applied stance on cognitive peculiarities of human decision-making drawing upon established judgment and decision-making research. The wide focus on deviations in human decision making from the rational choice model ranges from Simon's (1955) bounded rationality proposal and Tversky and Kahneman's (1974) heuristics and biases program to contemporary behavioural economics (Camerer et al. 2004) or "applied behavioural science" (Kahneman 2012, p. ix)".

Indeed, the number of options, the description of the attributes, and the use of a "default setting" determine some average foreseeable impact on the final decision (Johnson et al. 2012). A welldesigned choice architecture can "correct" irrational decision-making biases improving decisions in many sensitive domains such as health, finance, retirement provisions, environment, or education. On the basis of these successful applications, choice architecture has been proposed as the main instrument for the behavioural foundation of public policy (Shafir 2012). In the same perspective, in this paper we propose a choice architecture approach for supporting $\mathrm{SH}$ complex decision problems with structured methodologies of decision analysis. Indeed, handling such a situation requires the application of formal models, permitting to take into account all the many and delicate aspects of the decision problem at hand, ranging from the plurality of points of view to the heterogeneity of alternatives, without forgetting the multiplicity of stakeholders, experts, policy makers and decision makers involved. Therefore, the design of the procedure supporting such complex decision is fundamental for the overall quality of the final recommendation. With this aim, it is important to "architect" a decision procedure that takes into account bounded rationality (Simon 1955, Gigerenzer and Selten 2012) and psychological limitations (Kahneman 2011) of actors involved in the decision process. This permits to produce decisions that appear satisfying and convincing both for who takes the decisions and for who experiences its consequences. In this regard, some basic points informing the engineering of an effective and successful decision process are the following:

- maintaining the cognitive burden for the DM within the golden rule limits of the "magical number seven plus minus two" elements that our brain can hold in working memory (Miller 1956); 
- constructing a parsimonious model that permits to take into consideration all the most important aspects, but without losing the general vision of the model (Gigerenzer and Goldstein 1996);

- taking into account cognitive bias trying to avoid and to correct them when they do not permit to take good decisions (Hammond et al. 1999, Milkman et al. 2009);

- assessing an interactive procedure helping to compare alternatives in terms of their performances with respect to several points of view (Häubl and Trifts 2000, Murray et al. 2010).

\subsection{Parsimonious AHP methodology}

The AHP (Saaty 1990, 1980), is a MCDA method based on ratio scales for measuring performances on considered criteria and the importance of these criteria. AHP structures the problem at hand in a hierarchical way where the overall goal is set at the top of the hierarchy, and the alternatives being the object of the decision are placed at the bottom. The criteria on which the alternatives need to be evaluated are in the middle of the hierarchy, between the overall goal and the alternatives themselves; AHP uses a system of pairwise comparisons to measure the weights of the structure components and to rank the alternatives. There is a wide literature on AHP (Ishizaka and Labib 2011) together with applications in housing policies realm (Petrini et al. 2016), land evaluation (Cay and Uyan 2013, Thapa and Murayama 2008, Sklenicka P. 2006), territorial and environmental assessment (Qureshi and Harrison 2016, Campeol et al. 2016, Abastante and Lami 2013, AragonésBeltrán et al. 2010) and transport issues (Lami 2014, Lami and Abastante 2014, Lami et al. 2014, Bottero and Lami 2010, Pensa et al. 2014, 2013).

The basic idea of the methodology is the transformation of an objective numerical evaluation on a considered criterion in a subjective measure of attractiveness. Starting from comparisons between the performance on a small set of reference levels on each criterion and obtaining their priorities by means of the AHP, all the other levels (not provided as references) are got by interpolating the obtained priorities. Instead, according to the basic AHP methodology, it would be necessary to build the prioritization of each performance on the basis of the pairwise comparisons of each alternative with all the others. This would require asking the experts involved in the decision problem to supply a huge quantity of information, that is a comparison with respect to strength of the preference for all couples of alternatives with respect to all considered criteria.

For instance, in the case study here presented (section 3), where 21 alternatives and 10 criteria are counted, it would be necessary to ask 210 pairwise comparisons for each criterion. This sum up to a total of 2,100 pairwise comparisons. Realistically, this cannot be asked to the experts. This bottleneck is well known in the literature on AHP; for example, Saaty and Odzemir (2003) demonstrate that, using AHP, the number of elements to be considered should be no more than seven. Several methodologies have been proposed to handle this problem. Only to give some example, let us remember the following ones:

- $\quad$ Saaty (1977) proposed to construct cluster of no more than 7 similar alternatives, so that the DM would compare the alternatives within the clusters;

- $\quad$ Ishizaka (2012) proposed a variant where close clusters have a common alternative;

- several authors proposed procedures where the DM gives the pairwise comparisons on which he is more confident and the remaining comparisons are then estimated (Csató and Rónyai 
2016, Chen et al. 2015, Benítez et al. 2014, Gomez-Ruiz et al. 2010, Bozóki et al. 2010, Fedrizzi and Giove 2007, Harker 1987);

- other methodologies proposed in the literature compare alternatives with reference alternatives (Ishizaka 2012) or the best and the worst ones (Rezaei 2015).

In our methodology we adopted another approach, the Parsimonious AHP, that has been recently proposed (Abastante et al. 2018). It requires less and easier preference information focused on a set of reference alternatives selected with the cooperation of the DM, with the further important advantage of avoiding any rank reversal problem (Belton and Gear 1983) that is a very puzzling question for the basic AHP method (for a comprehensive review on this point see Maleki and S. Zahir 2013).

The Parsimonious AHP is composed of five steps (Abastante et al. 2018):

1. Structuring the problem and designing the model: Once clarified the goal of the decision problem, the alternatives must be identified and the criteria on which the alternatives are evaluated have to be specified;

2. Rating directly the alternatives: The DM, according to his knowledge and preferences, has to provide a direct rating of the alternatives on the considered criteria; for each criterion $j$ and each alternative $a$, by $r_{j}(a)$ we shall denote the rating assigned by the DM to the alternative $a$ on criterion $j$;

3. Selection of reference evaluations on each criterion: This operation is performed by the DM, with the support of the analyst. It should be mentioned that the definition of the reference evaluations could be fixed with a non "standardized" procedure, tailor-made, for each criterion of the decision problem; for each criterion $j$, the $t_{j}$ reference evaluations will be denoted by $\gamma_{j 1}, \ldots, \gamma_{j t_{j}}$;

4. Pairwise comparison of the reference evaluations: The prioritization of the reference evaluations is obtained by using "traditionally" the AHP method. The DM is asked to provide a series of pairwise comparisons in which two elements at a time are compared in terms of their contribution to the overall evaluation. Using AHP, for each criterion the DM is asked to compare each couple of reference levels indicating the preferred level and expressing the degree of preference with a verbal judgement on a nine points scale (Table 1) (Saaty and Ozdemir 2003, Saaty 1980). The numerical judgments established at each level of the hierarchy are entered in pairwise comparisons matrices, from which eigenvectors are calculated. The consistency of judgments is checked in order to ensure a reasonable level of consistency in terms of proportionality and transitivity. Saaty (1977) considers that a Consistency Ratio (CR) exceeding 10\% may indicate a set of judgments too inconsistent to be reliable and therefore he recommends to revise the evaluations. Another necessary control related to the obtained data regards the comparison between the normalized evaluations $u\left(\gamma_{\mathrm{js}}\right)$, for all $j=1, \ldots, n$, and the corresponding ratings $\gamma_{\mathrm{js}}$, to verify that the monotonicity of $u\left(\gamma_{\mathrm{js}}\right)$ with respect to $\gamma_{\mathrm{js}}$ is satisfied, that is, there is no situation in which $\gamma_{j s 1}>\gamma_{j s 2}$ while $u\left(\gamma_{j s 1}\right) \leq u\left(\gamma_{j s 2}\right)$. Also, in this case, the DM is suggested and guided to modify the rating or the pairwise comparisons in order to get consistency with respect to monotonicity between rating and priorities supplied by AHP.

Table 1. The nine levels of the comparison scale 


\begin{tabular}{|c|l|}
\hline LEVELS & \multicolumn{1}{c|}{ DEFINITIONS } \\
\hline 1 & Equal importance \\
\hline 2 & Equal - weak importance \\
\hline 3 & Weak importance \\
\hline 4 & Weak - strong importance \\
\hline 5 & Strong importance \\
\hline 6 & Strong - very strong importance \\
\hline 7 & Very strong importance \\
\hline 8 & Very strong - absolute importance \\
\hline 9 & Absolute importance \\
\hline
\end{tabular}

5. Prioritization of all evaluations by interpolation: All the other evaluations are prioritized by interpolation according to the priority values obtained for the reference evaluations at the previous point. For each $r_{j}(a) \in\left[\gamma_{j s}, \gamma_{j s+1}\right]$, the following value is therefore computed

$$
u\left(r_{j}(a)\right)=u\left(\gamma_{j s}\right)+\frac{u\left(\gamma_{j s+1}\right)-u\left(\gamma_{j s}\right)}{\gamma_{j s+1}-\gamma_{j s}}\left(r_{j}(a)-\gamma_{j s}\right)
$$

where $u\left(\gamma_{j s}\right)$ and $u\left(\gamma_{j s+1}\right)$ are the normalized values obtained for the reference evaluations $\gamma_{\mathrm{js}}$ and $\gamma_{j s+1}$ by applying the AHP method in step 4. While in the original AHP method the DM was asked to provide the pairwise comparison of all pairs of alternatives on all considered criteria, in this case he is asked to provide, at first, the rating of the alternatives on the considered criteria and to apply the AHP on a small subsets of reference evaluations defined for each criterion. In the case study illustrated in section 3, instead of asking 1,890 comparisons, only 72 pairwise comparisons were necessary.

\subsection{The Choquet integral and the NAROR}

Looking at the evaluations of the different alternatives on the considered criteria, the only information that can be obtained is the dominance relation for which an alternative $a$ dominates an alternative $b$ iff $a$ is at least as good as $b$ on all criteria and better in at least one of them. Anyway, the dominance relation leaves many alternatives incomparable since, in general, $a$ will be better than $b$ on some criteria and $b$ will be better than $a$ on the remaining ones. To have an estimate of the goodness of the alternatives w.r.t. the problem at hand, an aggregation of their evaluations has to be performed and in real world application, this is done by using a simple weighted sum

$$
\sum_{j=1}^{n} w_{j} g_{j}(a)
$$

where $g_{j}(a)$ is the performance of $a$ on criterion $g_{j}$, and $w_{1}, \ldots, w_{n}$ are the positive weights assigned to the criteria $g_{1}, \ldots, g_{n}$ so that they sum up to 1 .

The application of such a type of aggregation function assumes that the criteria are mutually preferentially independent (Keeney and Raiffa 1976). This is not always true since criteria can present a certain type of positive or negative interaction, as explained in the introduction. On one hand, two criteria are positively interacting if the weights assigned to them together is greater than 
the sum of the weights assigned to them singularly; on the other hand, two criteria are negatively interacting if the weights assigned to them together is lower than the sum of the weights assigned to them singularly. In order to take into account these interactions, non-additive integrals are used in literature and the Choquet integral is the most well-known (Grabisch 1996, Choquet 1953).

Differently from the weighted sum which application implies the knowledge of the weights assigned to the single criteria, the Choquet integral is based on a capacity being a set function $\mu$ assigning a value to each subset of considered criteria. $\mu$ has to satisfy monotonicity constraints (the weight assigned to a set of criteria $B$ has to be no lower than the weight assigned to a set of criteria $C$ if $B$ is a subset of $C$ ) and normalization constraints (the weight assigned to the empty set of criteria is zero, while the weight assigned to the totality of criteria has to be equal to one). In order to make things easier, in general a Möbius transformation $m$ of the capacity $\mu$ (Rota 1964) ${ }^{1}$ and $k$ additive measures (Grabisch 1997) are considered ${ }^{2}$.

In this context, it is relevant to underline that the importance of a criterion is not dependent on its own weight only, but also on its contribution to all coalitions of criteria. For this reason, the Shapley (Shapley 1953) and the interaction (Murofushi and Soneda 1993) indices are used. They compute a value for each criterion and for each pair of criteria being representative of their importance.

The Choquet integral of an alternative $a$ in terms of Möbius and considering a 2-additive capacity is the following:

$$
C h_{\mu}(a)=\sum_{j=1}^{n} m\left(\left\{g_{j}\right\}\right) g_{j}(a)+\sum_{\{i, j\} \subseteq G} m\left(\left\{g_{i}, g_{j}\right\}\right) \min \left\{g_{i}(a), g_{j}(a)\right\}
$$

Analogously, the Shapley value of criterion $g_{j}$ (denoted by $\varphi\left(\left\{g_{j}\right\}\right)$ ) and the interaction value of the pair of criteria $\left\{g_{i}, g_{j}\right\}$ (denoted by $\varphi\left(\left\{g_{i}, g_{j}\right\}\right)$ ), are computed as follows:

$$
\varphi\left(\left\{g_{i}\right\}\right)=m\left(\left\{g_{i}\right\}\right)+\sum_{g_{j} \in G \backslash\left\{g_{i}\right\}} \frac{m\left(\left\{g_{i}, g_{j}\right\}\right)}{2}, \quad \varphi\left(\left\{g_{i}, g_{j}\right\}\right)=m\left(\left\{g_{i}, g_{j}\right\}\right)
$$

The use of the Choquet integral in eq. (3), involves the knowledge of the weights of single criteria $\left(m\left(\left\{g_{j}\right\}\right)\right)$ as well as the weights of each unordered pair of criteria $\left(m\left(\left\{g_{i}, g_{j}\right\}\right)\right)$. To this hand, a direct or an indirect technique can be used. In the direct one, the DM is able to provide numerical values to all these parameters. However, this is a quite complex issue for the huge number of parameters involved as well as for their meaning. For this reason, the indirect technique is preferred in practice. In this case, the DM provides some preferences in terms of pairwise comparisons between alternatives as well as in terms of importance of criteria from which parameters compatible with these preferences can be inferred (Angilella et al. 2010a, Marichal and Roubens 2000). These

\footnotetext{
${ }^{1}$ The Möbius transformation $m$ of a capacity $\mu$ is a set function $m: 2^{G} \rightarrow[0,1]$ such that $\mu(S)=\sum_{T \subseteq S} m(T)$ and, therefore, $m(S)=\sum_{T \subseteq S}(-1)^{|S-T|} \mu(T)$. The monotonicity and normalization constraints of $\mu$ are then transformed in terms of $m$ (for some more technical details see Marichal and Roubens 2000).

${ }^{2}$ A capacity $\mu$ is said $k$-additive iff its Möbius transformation is such that $m(T)=0$ for all subsets of criteria $T$ having cardinality greater than $k$.
} 
preferences are therefore translated into constraints involving the same considered parameters ${ }^{3}$. If feasible, the set of constraints defines a family of parameters vectors compatible with preferences expressed by the DM. In general, there is a plurality of parameters vectors (we will call one of them " $a$ model") so that, the choice of only one of them could be considered arbitrary to some extent. For this reason, Robust Ordinal Regression (Corrente et al. 2013, Greco et al. 2008) takes into account all the models compatible with the preferences provided by the DM by defining a necessary $\left(\gtrsim^{N}\right)$ and a possible $\left(\gtrsim^{P}\right)$ preference relation on the set of alternatives $A$. Given two alternatives $a$ and $b$, $a$ is necessarily preferred to $b$ iff $a$ is at least as good as $b$ for all compatible models (denoted by $a \succsim^{N} b$ ), while $a$ is possibly preferred to $b$ iff $a$ is at least as good as $b$ for at least one compatible model (denoted by $a \gtrsim^{P} b$ ). The two preference relations are computed by solving at most two Linear Programs (LP) problems for each pair of alternatives (see Corrente et al. 2016 for the description of the LPs that need to be solved). The application of the ROR to the Choquet integral preference model is called Non-Additive Robust Ordinal Regression (NAROR; Angilella et al. 2010a).

The information gathered by the necessary and possible preference relation is therefore summarized by the use of the most representative model (Angilella et al. 2010b). This is a model compatible with the preferences provided by the DM that maximizes the difference between alternatives $a$ and $b$ such that $a$ is necessarily preferred to $b$ but it is not true the vicevers $a$, in so doing minimizing, at the same time, the difference between alternatives $a$ and $b$ such that neither $a$ is necessarily preferred to $b$ nor the viceversa (see Angilella et al. 2010b for a description of the computation of the most representative model in case of the Choquet integral).

\subsection{Synthesis of the whole methodology}

In summary, the new approach permits to organize the information by alternating stages of dialogue and calculation. The dialogue stages aim at collecting information directly from the DM, which can reveal their preferences about the alternatives and the criteria at stake. The DM preferences are in turn taken into account in the calculation stages. The procedure is articulated in eight main phases, as shown in Table 2 .

Table 2. Synthesis of the steps

\begin{tabular}{|c|c|c|}
\hline PHASE & ACTIVITY & THEORY/APPROACH/KNOWLEDGE \\
\hline 1 & $\begin{array}{l}\text { Structuring the problem and designing the } \\
\text { model }\end{array}$ & $\begin{array}{l}\text { Definition of the goal, the alternatives and the criteria to } \\
\text { evaluate the alternatives }\end{array}$ \\
\hline 2 & $\begin{array}{l}\text { Rating the alternatives on each considered } \\
\text { criterion }\end{array}$ & Knowledge and preferences of the DM \\
\hline 3 & $\begin{array}{l}\text { Selection of reference evaluations on each } \\
\text { criterion }\end{array}$ & $\begin{array}{l}\text { Knowledge and preferences of the DM, that could be } \\
\text { also based on the literature }\end{array}$ \\
\hline
\end{tabular}

\footnotetext{
${ }^{3}$ The preference of $a$ over $b$ stated by the DM is translated into the constraint $C h_{\mu}(a) \geq C h_{\mu}(b)+\varepsilon$, where $\varepsilon$ is a fictitious variable greater than zero. The indifference between $a$ and $b$ is translated into the constraint $C h_{\mu}(a)=$ $C h_{\mu}(b)$. The preference of criterion $g_{i}$ over criterion $g_{j}$ is translated into the constraint $\varphi\left(\left\{g_{i}\right\}\right) \geq \varphi\left(\left\{g_{j}\right\}\right)+\varepsilon$ and, finally, positive (negative) interaction between criteria $g_{i}$ and $g_{j}$ is translated into the constraint $\varphi\left(\left\{g_{i}, g_{j}\right\}\right) \geq \varepsilon(\leq$ $-\varepsilon$ ). See Angilella et al. 2010a and Corrente et al. 2016 for more information on the translation of the preference information in constraints of the model.
} 


\begin{tabular}{|c|c|c|}
\hline 4 & $\begin{array}{c}\text { Pairwise comparison of the reference } \\
\text { evaluations obtaining normalised values }\end{array}$ & AHP \\
\hline 5 & $\begin{array}{c}\text { Prioritization of all evaluations by } \\
\text { interpolation }\end{array}$ & Interpolation \\
\hline 6 & Interaction between considered criteria & $\begin{array}{c}\text { Knowledge and preferences of the DM (that could be } \\
\text { also based on the literature) + Choquet integral }\end{array}$ \\
\hline 7 & $\begin{array}{c}\text { Overall (possibly partial) ranking of criteria } \\
\text { in terms of their importance }\end{array}$ & $\begin{array}{c}\text { Knowledge and preferences of the DM (that could also } \\
\text { be based on the literature) + Shapley index }\end{array}$ \\
\hline 8 & $\begin{array}{c}\text { Construction, presentation and discussion of } \\
\text { the final alternatives ranking }\end{array}$ & $\begin{array}{c}\text { Choquet integral within NAROR+representative value } \\
\text { function }\end{array}$ \\
\hline
\end{tabular}

\section{The case study}

The contemporary presence of research needs and a professional problem led us to deal with the case study related to the selection of SH projects in Italy.

The nature of the real decision process conducted by the $\mathrm{PH}$ is complex and requires a detailed consideration of internal and external factors involving a number of decision criteria and alternatives. In particular, the projects submitted to the $\mathrm{PH}$ are characterized by a double identity:

i) a technical identity related to the construction or redesign of the existing buildings from an architectural point of view to respond to the housing needs;

ii) a social identity related to the social support needed by the people hosted in the SH projects. Indeed, one of the distinctive features of the $\mathrm{SH}$ is the presence of activities of social support devoted to beneficiaries in order to integrate them in the society.

Due to the aforementioned intrinsic identities, each $\mathrm{SH}$ project is unique, making the selection process extremely delicate and difficult for the $\mathrm{PH}$.

It is important to underline that the PH acts as a DM for the decision process in exam. In order to properly consider the technical and social identities of the $\mathrm{SH}$ projects proposed, the $\mathrm{PH}$ is composed by architects, engineers, evaluators, psychologists and sociologists working together with the aim of deciding which are the SH projects worthy of funding. In order to avoid misunderstanding, hereinafter we will refer to the PH as the DM.

The paper's authors acted as "choice architects" (Thaler and Sunstein 2008), organising in a different way the context in which the DM has to take the decision. As revealed by the social science, "as the choices become more numerous and/or vary on more dimensions, people are more likely to adopt simplifying strategies. [...] As alternatives become more numerous and more complex, choice architects have more to think about and more work to do and are much more likely to influence choices" (Thaler et al. 2010). It is important to stress out that the current procedure adopted by the DM is not a simplified strategy. The challenge for us was to test an alternative methodological framework and verify if it was able to reduce the decisional effort for the DM considering, at the same time, all the crucial aspects of the problem.

The specific characteristics making the aforementioned process extremely challenging are:

i) the huge amount of alternatives and decision criteria to be evaluated and compared;

ii) the heterogeneous nature of quantitative and qualitative decision criteria;

iii) the simultaneous presence of technical and social criteria;

iv) the interdependence of the criteria; 
v) the uniqueness of the SH projects;

vi) the possibility to interface with the DM involved in the actual selection process.

All the aforementioned reasons solicited the application of our methodological approach of choice architecture for architecture choices. The ranking process here presented involved eight interactions with the DM, from September year to June year, making the process nine months long.

Due to the confidential nature of the DM data, it took some time to start up the process. The first interaction aimed at illustrating the methodological approach in order to give the DM all the needed information to decide whether they were interested or not in our research. The second interaction was devoted to solve confidentiality matters related to the SH projects so far financed from the DM. After the aforementioned discussions, the DM showed to be interested in the methodological approach and therefore they gave us access to the data of SH projects.

It is important to underline that the ranking process reported in the next sections constitutes a methodological application based on $\mathrm{SH}$ projects already financed. Nevertheless, thanks to the proved availability of the DM, we aim at applying it during a future actual selection process.

\subsection{Structuring of the decision process}

In order to start the ranking process, it was first necessary to understand the constraints that the DM has to take into account. During an interaction with the DM, different levels of constraints emerged: 1) budgets limits imposed by the CSP; 2) attention to the territorial planning as the DM usually prefers projects located where there are no similar interventions; 3) attention to the final beneficiaries of the SH projects proposed in order to cover a wide spectrum of social needs.

During the same interaction, we defined the set of alternative SH projects to be considered. In line with the DM suggestions, we decided to apply the methodological approach to $21 \mathrm{SH}$ projects chosen according to three main logics as: availability of homogeneous information for each project, location (Figure 1) and intrinsic characteristics of the projects (Table 3). 


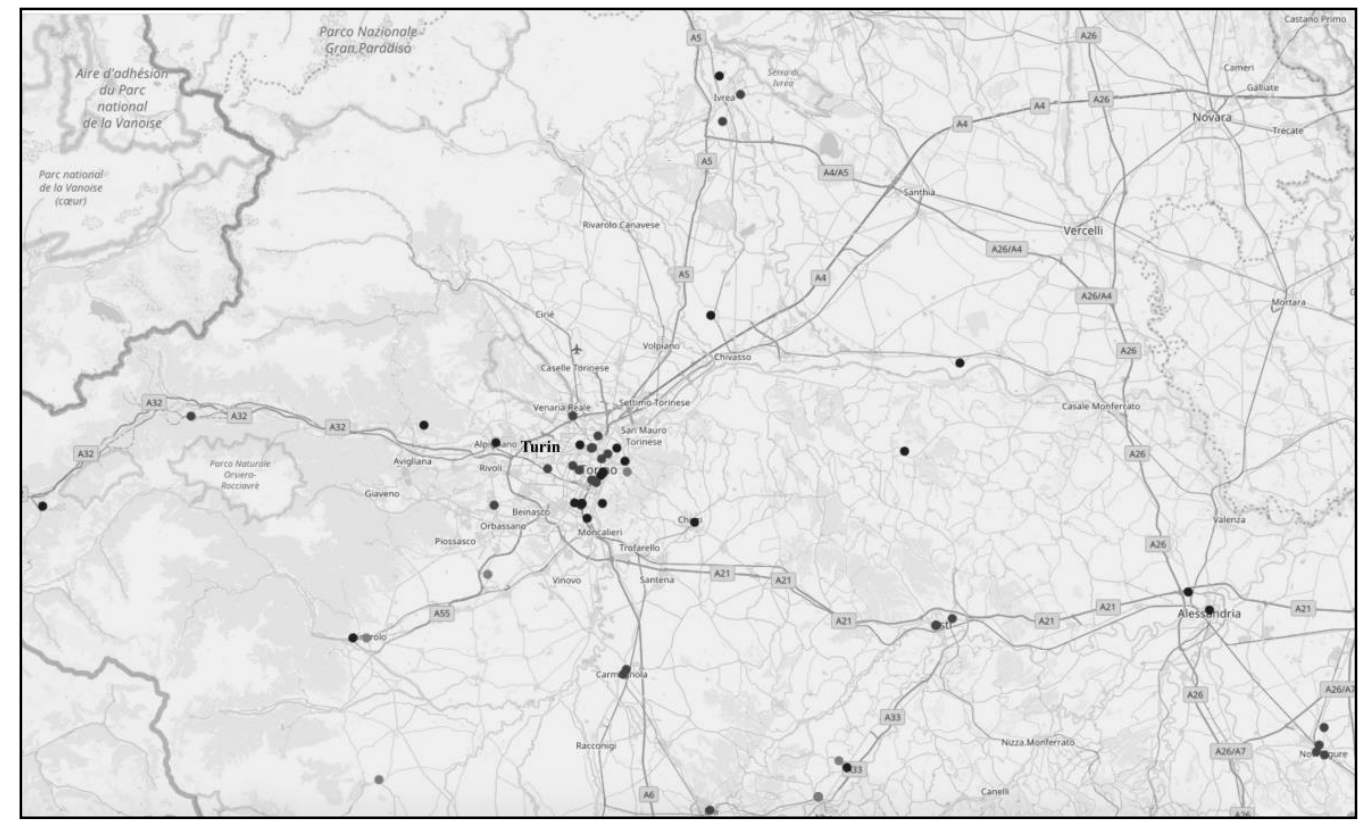

Figure 1. Location of the SH projects

As showed in Figure 1, the $21 \mathrm{SH}$ projects are located in the Piedmont Region (Italy); among them, 9 are in the metropolitan area of Turin and 6 in the Turin city.

Table 3 reports a synthetic description of the main intrinsic characteristics of the 21 projects in exam. The acronyms of each characteristic are reported in the third column to facilitate the reading of Table 4.

Table 3. Description of the SH characteristics

\begin{tabular}{|c|c|c|c|}
\hline \multicolumn{2}{|c|}{ CHARACTERISTICS } & \multicolumn{2}{|c|}{ SPECIFIC DESCRIPTION } \\
\hline \multirow{2}{*}{$\begin{array}{l}\text { Housing supply } \\
\text { typology }\end{array}$} & \multirow{2}{*}{$\begin{array}{l}\text { It refers to the type of rental } \\
\text { contract stipulated with the } \\
\text { beneficiaries of the projects. }\end{array}$} & $\begin{array}{l}\text { Temporary } \\
\text { (HST) }\end{array}$ & Maximum 18 months \\
\hline & & $\begin{array}{l}\text { Long period } \\
\text { (HSL) }\end{array}$ & From 1 to 4 years \\
\hline \multirow{3}{*}{ Compartments } & \multirow{3}{*}{$\begin{array}{l}\text { It refers to the dimensions of the } \\
\text { projects in terms of } \\
\text { compartments. It gives an } \\
\text { indication of the possible number } \\
\text { of beds provided by the project. }\end{array}$} & $\begin{array}{l}\text { One/two rooms } \\
\text { (CO) }\end{array}$ & Small project (1/4 beds) \\
\hline & & $\begin{array}{c}\text { Three/four rooms } \\
\text { (CT) }\end{array}$ & Medium project (5/8 beds) \\
\hline & & $\begin{array}{l}\text { More than four rooms } \\
\text { (CF) }\end{array}$ & Big projects (more than 8 beds) \\
\hline Target & $\begin{array}{l}\text { It refers to the categories of } \\
\text { beneficiaries to which the projects }\end{array}$ & $\begin{array}{c}\text { Elderly } \\
\text { (TE) }\end{array}$ & People with more than 65 years. \\
\hline
\end{tabular}




\begin{tabular}{|c|c|c|c|}
\hline & are destined to. & $\begin{array}{l}\text { Single parent women } \\
\text { (TSW) }\end{array}$ & $\begin{array}{l}\text { Single women with at least one } \\
\text { child }\end{array}$ \\
\hline & & $\begin{array}{c}\text { Single parent men } \\
\text { (TSM) }\end{array}$ & Single men with at least one child \\
\hline & & $\begin{array}{l}\text { Couples with children } \\
\text { (TCC) }\end{array}$ & $\begin{array}{l}\text { Young couples with at least one } \\
\text { child }\end{array}$ \\
\hline & & $\begin{array}{c}\text { Students } \\
\text { (TS) }\end{array}$ & $\begin{array}{c}\text { Students able to afford a minimum } \\
\text { rent }\end{array}$ \\
\hline & & $\begin{array}{l}\text { Men } \\
\text { (TM) }\end{array}$ & Men facing social fragility \\
\hline & & $\begin{array}{c}\text { Women } \\
\text { (TW) }\end{array}$ & Women facing social fragility \\
\hline \multirow{5}{*}{$\begin{array}{c}\text { Activities of } \\
\text { social support }\end{array}$} & \multirow{5}{*}{$\begin{array}{l}\text { Activities provided by the } \\
\text { projects in terms of social support } \\
\text { and aimed at an effective re- } \\
\text { inclusion of the beneficiaries in } \\
\text { the society. }\end{array}$} & $\begin{array}{l}\text { Money use } \\
\text { (ASM) }\end{array}$ & $\begin{array}{l}\text { Activities aimed at teaching how to } \\
\text { rationally use the money. }\end{array}$ \\
\hline & & $\begin{array}{l}\text { Professionalizing activities } \\
\text { (ASP) }\end{array}$ & Teaching of manual work. \\
\hline & & $\begin{array}{c}\text { Job seeking support } \\
(\mathbf{A S J})\end{array}$ & $\begin{array}{l}\text { Support in finding a job in the } \\
\text { current market. }\end{array}$ \\
\hline & & $\begin{array}{c}\text { House seeking support } \\
\text { (ASH) }\end{array}$ & $\begin{array}{l}\text { Support in finding a house in the } \\
\text { current market. }\end{array}$ \\
\hline & & $\begin{array}{l}\text { Family mediation support } \\
\text { (ASF) }\end{array}$ & $\begin{array}{l}\text { Presence of a psychologist that } \\
\text { helps the relations among family } \\
\text { members in dangerous social } \\
\text { situations. }\end{array}$ \\
\hline
\end{tabular}

It is interesting to notice that the characteristics reported in Table 3 perfectly reflect the double identity of the SH projects. In this sense, technical and social characteristics coexist in the same project making the decision process challenging.

According to Table 3, a synthetic description of the $21 \mathrm{SH}$ projects considered is reported in Table 4.

Despite we have all the data available for each project, we opted for an aggregated return due to confidentiality constrictions imposed by the DM. For the same reason, in Table $\mathbf{4}$ and following, the column "ID" identifies the SH projects considered through some codes instead of their actual names.

Table 4. Description of the SH projects considered

\begin{tabular}{|c|c|c|c|c|c|c|c|c|c|c|c|c|c|c|c|c|c|}
\hline \multirow[b]{2}{*}{ ID } & \multicolumn{2}{|c|}{$\begin{array}{c}\text { HOUSING } \\
\text { SUPPLY } \\
\text { TYPOLOGY }\end{array}$} & \multicolumn{3}{|c|}{ COMPARTMENTS } & \multicolumn{7}{|c|}{ TARGET } & \multicolumn{5}{|c|}{$\begin{array}{l}\text { ACTIVITIES OF SOCIAL } \\
\text { SUPPORT }\end{array}$} \\
\hline & HST & HSL & $\mathrm{CO}$ & CT & CF & TE & TSW & TSM & TCC & TS & TM & TW & ASM & ASP & ASJ & ASH & ASF \\
\hline P1 & $\checkmark$ & & $\checkmark$ & & & & $\checkmark$ & $\checkmark$ & $\checkmark$ & $\checkmark$ & $\checkmark$ & $\checkmark$ & $\checkmark$ & $\checkmark$ & & $\checkmark$ & \\
\hline $\mathbf{P 2}$ & $\checkmark$ & & $\checkmark$ & & & & $\checkmark$ & & $\checkmark$ & & & $\checkmark$ & $\checkmark$ & $\checkmark$ & $\checkmark$ & $\checkmark$ & $\checkmark$ \\
\hline P3 & $\checkmark$ & & $\checkmark$ & & $\checkmark$ & & $\checkmark$ & & $\checkmark$ & & & $\checkmark$ & $\checkmark$ & $\checkmark$ & $\checkmark$ & $\checkmark$ & $\checkmark$ \\
\hline $\mathbf{P 4}$ & & $\checkmark$ & & $\checkmark$ & $\checkmark$ & $\checkmark$ & $\checkmark$ & $\checkmark$ & $\checkmark$ & & $\checkmark$ & $\checkmark$ & $\checkmark$ & & & $\checkmark$ & \\
\hline P5 & $\checkmark$ & & & & $\checkmark$ & & & & & & & $\checkmark$ & & & & & \\
\hline P6 & $\checkmark$ & & $\checkmark$ & & & $\checkmark$ & $\checkmark$ & $\checkmark$ & $\checkmark$ & $\checkmark$ & $\checkmark$ & $\checkmark$ & $\checkmark$ & $\checkmark$ & & & \\
\hline P7 & $\checkmark$ & & & & $\checkmark$ & $\checkmark$ & & & & & $\checkmark$ & $\checkmark$ & & $\checkmark$ & $\checkmark$ & & \\
\hline P8 & & $\checkmark$ & $\checkmark$ & $\checkmark$ & & $\checkmark$ & $\checkmark$ & $\checkmark$ & $\checkmark$ & & $\checkmark$ & $\checkmark$ & & & & $\checkmark$ & \\
\hline P9 & $\checkmark$ & $\checkmark$ & $\checkmark$ & & & $\checkmark$ & $\checkmark$ & $\checkmark$ & $\checkmark$ & $\checkmark$ & $\checkmark$ & $\checkmark$ & $\checkmark$ & $\checkmark$ & $\checkmark$ & $\checkmark$ & $\checkmark$ \\
\hline P10 & $\checkmark$ & & $\checkmark$ & $\checkmark$ & & & & & & $\checkmark$ & $\checkmark$ & & $\checkmark$ & $\checkmark$ & $\checkmark$ & $\checkmark$ & $\checkmark$ \\
\hline
\end{tabular}




\begin{tabular}{|l|l|l|l|l|l|l|l|l|l|l|l|l|l|l|l|l|l|} 
P11 & $\checkmark$ & & $\checkmark$ & & & & $\checkmark$ & $\checkmark$ & & & $\checkmark$ & $\checkmark$ & $\checkmark$ & $\checkmark$ & $\checkmark$ & $\checkmark$ & $\checkmark$ \\
\hline P12 & $\checkmark$ & & $\checkmark$ & & & & $\checkmark$ & & & & & $\checkmark$ & & $\checkmark$ & & & \\
\hline P13 & $\checkmark$ & & $\checkmark$ & & & & $\checkmark$ & & & & & $\checkmark$ & $\checkmark$ & $\checkmark$ & & & \\
\hline P14 & $\checkmark$ & & $\checkmark$ & & & $\checkmark$ & $\checkmark$ & & $\checkmark$ & & & $\checkmark$ & $\checkmark$ & & $\checkmark$ & $\checkmark$ & $\checkmark$ \\
\hline P15 & $\checkmark$ & & $\checkmark$ & & & & & & $\checkmark$ & & $\checkmark$ & & $\checkmark$ & $\checkmark$ & $\checkmark$ & $\checkmark$ & $\checkmark$ \\
\hline P16 & $\checkmark$ & & $\checkmark$ & & & & $\checkmark$ & $\checkmark$ & & & $\checkmark$ & $\checkmark$ & $\checkmark$ & $\checkmark$ & $\checkmark$ & & \\
\hline P17 & $\checkmark$ & $\checkmark$ & $\checkmark$ & $\checkmark$ & $\checkmark$ & $\checkmark$ & $\checkmark$ & & $\checkmark$ & & $\checkmark$ & $\checkmark$ & $\checkmark$ & & $\checkmark$ & $\checkmark$ & $\checkmark$ \\
\hline P18 & & $\checkmark$ & $\checkmark$ & $\checkmark$ & & $\checkmark$ & & & & & $\checkmark$ & $\checkmark$ & $\checkmark$ & & & $\checkmark$ & $\checkmark$ \\
\hline P19 & & $\checkmark$ & $\checkmark$ & $\checkmark$ & & $\checkmark$ & $\checkmark$ & $\checkmark$ & $\checkmark$ & & $\checkmark$ & $\checkmark$ & & & & $\checkmark$ & \\
\hline P20 & $\checkmark$ & $\checkmark$ & $\checkmark$ & & & $\checkmark$ & $\checkmark$ & $\checkmark$ & $\checkmark$ & $\checkmark$ & $\checkmark$ & $\checkmark$ & $\checkmark$ & & & $\checkmark$ & $\checkmark$ \\
\hline P21 & $\checkmark$ & & $\checkmark$ & $\checkmark$ & $\checkmark$ & $\checkmark$ & $\checkmark$ & $\checkmark$ & $\checkmark$ & & $\checkmark$ & $\checkmark$ & $\checkmark$ & $\checkmark$ & & $\checkmark$ & $\checkmark$ \\
\hline
\end{tabular}

From Table 4, it is possible to notice that the $21 \mathrm{SH}$ projects show different technical and social characteristics. It emerges that:

- In terms of housing supply typology, the vast majority of the projects offer a temporary contract ( 17 out of 21 , characteristic HST);

- The near totality of the projects (18 out of 21) are primarily destined to small families or individuals since they offer from 1 to 4 beds (characteristic CO). This information can be read together with the target characteristics of the projects highlighting that, the majority of the projects is destined to single parents (characteristic TSW) and/or single women (characteristic TW);

- As far as it concerns the activities of social support, the majority of the projects offer diverse social activities (15 out of 21). This characteristic is fundamental in SH projects and it is a complex element in terms of decision process. In fact, since the social activities are usually designed ad hoc for each SH project, it is not simply possible to affirm that the more social activities are put into play, the better the project is. In order to catch this complexity in the assessment framework, we defined the social activities as different interrelated decision criteria (i.e. clarity and innovation, human resources, social tools and methodology) as reported in Table 5).

According to the description of Table 4, the considered $21 \mathrm{SH}$ projects are heterogeneous but comparable at the same time.

After having decided the sample of $\mathrm{SH}$ projects to be compared, it was necessary to define the decision criteria on which the projects have to be compared. It is interesting to stress out that, during a further interaction with the DM, he rethought his own procedure, starting from the actual selection process involving 18 decision criteria. As a matter of fact, the DM decided to aggregate and reduce the decision criteria from 18 to 10 since he realized that some criteria were redundant.

The decision criteria are described in Table 5, where the column "Max Score" reports the maximum score that each project can reach on the considered criterion and the arrows indicate if it is a criterion to maximise or minimise.

Table 5. Description of the decision criteria

\begin{tabular}{|c|c|c|c|}
\hline CRITERIA & \multicolumn{2}{|c|}{ DESCRIPTION } & MAX SCORE \\
\hline $\begin{array}{c}\text { Overall } \\
\text { consistency } \\
(\mathrm{C} 1)\end{array}$ & $\begin{array}{c}\text { This criterion considers the overall consistency of the project } \\
\text { spaces. It comprises: the location of the initiative, the } \\
\text { integration of different uses and the presence of shared } \\
\text { rooms. }\end{array}$ & 10 \\
\hline
\end{tabular}




\begin{tabular}{|c|c|c|}
\hline $\begin{array}{l}\text { Quality of the } \\
\text { design project } \\
\text { (C2) }\end{array}$ & $\begin{array}{l}\text { This criterion considers different aspects of the design } \\
\text { project. It comprises: the flexibility and modularity of the } \\
\text { architecture, the accessibility of the building for disabled } \\
\text { people and the energy performances of the building. }\end{array}$ & 15 \\
\hline $\begin{array}{l}\text { Beds } \\
\text { (C3) }\end{array}$ & Overall beds provided by the initiative. & 10 \\
\hline $\begin{array}{l}\text { Economic } \\
\text { consistency } \\
\text { (C4) }\end{array}$ & $\begin{array}{l}\text { This criterion assesses the economic aspects of the design } \\
\text { project. It comprises: the fairness of the parametric costs, the } \\
\text { co-financing amounts and the usefulness of the economic } \\
\text { contribution. }\end{array}$ & 15 \\
\hline $\begin{array}{l}\text { Euros/beds } \\
\quad \text { (C5) }\end{array}$ & $\begin{array}{l}\text { Total amount of euros needed with respect to the number of } \\
\text { beds provided by the initiative. }\end{array}$ & $20.000 € /$ beds \\
\hline $\begin{array}{l}\text { Clarity and } \\
\text { innovation } \\
\text { (C6) }\end{array}$ & $\begin{array}{l}\text { Clarity of the objectives and coherence/innovation with } \\
\text { respect to the actions planned. }\end{array}$ & 15 \\
\hline $\begin{array}{l}\text { Human } \\
\text { resources } \\
(\mathrm{C} 7)\end{array}$ & $\begin{array}{l}\text { Information on the amount of human resources and their } \\
\text { roles with respect to the initiative. }\end{array}$ & 10 \\
\hline $\begin{array}{l}\text { Social tools } \\
\text { and } \\
\text { methodologies } \\
\quad \text { (C8) }\end{array}$ & $\begin{array}{c}\text { Tools and methodologies adopted to manage the social } \\
\text { project. }\end{array}$ & 25 \\
\hline $\begin{array}{l}\text { Economic } \\
\text { sustainability } \\
\text { (C9) }\end{array}$ & $\begin{array}{c}\text { Information about the long-term sustainability of the } \\
\text { initiative. }\end{array}$ & 10 \\
\hline $\begin{array}{l}\text { Synergies } \\
(\mathrm{C} 10)\end{array}$ & Partnerships and networks on the territory of intervention. & 15 \\
\hline
\end{tabular}

From Table 5, it is possible to notice that the DM decided to consider 5 criteria with social connotation and 5 criteria with technical connotation in order to balance the ranking process.

\subsection{Rating the alternatives}

The SH projects and their evaluations with respect to the considered decision criteria are shown in Table 6. It is important to stress out that the reported performances' evaluations of the SH projects have been assigned by the DM during the actual selection processes. For this reason, the phase concerning the direct rating of the alternatives, which is the second step of the method, has been done quite quickly thanks to previous ranking. The performances' evaluations have been in turn converted and aggregated in order to consider the decision criteria described in Table 5.

Table 6. Set of considered SH projects and evaluations

\begin{tabular}{|c|c|c|c|c|c|c|c|c|c|c|}
\hline \multirow{2}{*}{ ID } & \multicolumn{10}{|c|}{ DECISION CRITERIA } \\
\hline & C1 & C2 & C3 & C4 & C5 & C6 & C7 & C8 & C9 & $\mathbf{C 1 0}$ \\
\hline P1 & 9 & 12 & 24 & 10 & 7,500 & 12 & 8 & 18 & 8 & 8 \\
\hline $\mathbf{P 2}$ & 10 & 0 & 6 & 5 & 8,450 & 9 & 6 & 12 & 10 & 13 \\
\hline P3 & 8 & 11 & 8 & 8 & 17,000 & 10 & 6 & 15 & 2 & 15 \\
\hline
\end{tabular}




\begin{tabular}{|c|c|c|c|c|c|c|c|c|c|c|}
\hline P4 & 10 & 8 & 20 & 10 & 2,900 & 13 & 8 & 10 & 8 & 10 \\
\hline P5 & 8 & 6 & 6 & 8 & 17,500 & 10 & 6 & 20 & 2 & 5 \\
\hline P6 & 5 & 1 & 8 & 6 & 9,500 & 14 & 10 & 25 & 8 & 10 \\
\hline P7 & 10 & 6 & 5 & 4 & 3,260 & 12 & 8 & 17 & 7 & 5 \\
\hline P8 & 10 & 8 & 10 & 7 & 7,500 & 10 & 6 & 12 & 3 & 13 \\
\hline P9 & 7 & 4 & 20 & 9 & 4,750 & 11 & 8 & 13 & 3 & 9 \\
\hline P10 & 8 & 8 & 21 & 7 & 6,667 & 11 & 10 & 15 & 0 & 14 \\
\hline P11 & 9 & 8 & 8 & 8 & 12,500 & 15 & 9 & 23 & 5 & 10 \\
\hline P12 & 10 & 5 & 8 & 9 & 20,000 & 1 & 2 & 2 & 0 & 4 \\
\hline P13 & 10 & 13 & 15 & 8 & 8,000 & 9 & 5 & 14 & 10 & 11 \\
\hline P14 & 10 & 4 & 8 & 7 & 15,000 & 7 & 6 & 12 & 6 & 6 \\
\hline P15 & 8 & 5 & 7 & 6 & 8,714 & 14 & 8 & 21 & 2 & 12 \\
\hline P16 & 8 & 11 & 8 & 9 & 12,500 & 7 & 6 & 15 & 0 & 10 \\
\hline P17 & 7 & 4 & 24 & 7 & 5,000 & 6 & 7 & 15 & 6 & 10 \\
\hline P18 & 7 & 2 & 4 & 7 & 13,750 & 13 & 10 & 22 & 0 & 1 \\
\hline P19 & 9 & 14 & 23 & 10 & 6,957 & 9 & 5 & 14 & 6 & 6 \\
\hline P20 & 8 & 8 & 23 & 6 & 7,609 & 6 & 2 & 13 & 5 & 8 \\
\hline P21 & 5 & 7 & 15 & 5 & 4,000 & 6 & 3 & 5 & 2 & 3 \\
\hline
\end{tabular}

\subsection{Selection of reference evaluations on each criterion and their pairwise comparison}

In order to use the Choquet integral preference model and, consequently, the NAROR, the evaluations of each project with respect to the decision criteria need to be expressed on a common scale.

This is possible by using the AHP (Saaty 1990, Saaty 1980) but it would require 210 pairwise comparisons for each of the 10 criteria, leading to a total of 2,100 pairwise comparisons. In order to reduce the cognitive effort of the DM, we proposed to apply the AHP only to a set of reference evaluations on the scale of each criterion and to determine the normalized value of the evaluations on the $21 \mathrm{SH}$ projects by using the procedure described in Section 2.2.

Consequently, we carried out two different discussions with the DM to define the set of reference evaluations (phase 3 of the methodology summarized in Table 2) and we asked him to compare the values shown in Table 7 (phase 4 of the methodology summarized in Table 2). It should be mentioned that the definition of the reference evaluations could be fixed with a non "standardized" procedure tailor-made for each criterion of the decision problem. In our case, this developed an interesting discussion among the technical and social experts of the PH: approaching their decisions in this way, they were forced to rethink the entire evaluation process and/or to clarify some steps that are often intuitively conducted.

Table 7. Reference evaluations for the considered criteria

\begin{tabular}{|c|c|c|c|c|c|c|c|c|c|}
\hline C1 & C2 & C3 & C4 & C5 & C6 & C7 & C8 & C9 & C10 \\
\hline 0 & 0 & 4 & 0 & 2,500 & 0 & 0 & 0 & 0 & 0 \\
\hline 5 & 5 & 7 & 4 & 5,000 & 7 & 5 & 10 & 5 & 7 \\
\hline 8 & 8 & 10 & 8 & 10,000 & 11 & 7 & 20 & 7 & 11 \\
\hline 10 & 10 & 20 & 10 & 15,000 & 15 & 10 & 25 & 10 & 15 \\
\hline
\end{tabular}




\begin{tabular}{|l|l|l|l|l|l|l|l|l|l|}
\hline & 15 & 25 & & 20,000 & & & & & \\
\hline
\end{tabular}

As a consequence, the pairwise comparisons asked to the $\mathrm{DM}$ were

- 6 for the 4 reference evaluations of the criteria C1, C4, C6, C7, C8, C9 and C10,

- 10 for the 5 reference evaluations of the criteria $\mathrm{C} 2, \mathrm{C} 3$ and $\mathrm{C} 5$,

which gave a total of 72 pairwise comparisons.

Two examples of the pairwise comparisons given by the DM during the aforementioned discussions are reported in Table 8.

Table 8. Pairwise comparison matrices for the considered decision criteria

\begin{tabular}{|l|l|l|l|l|l|l|l|l|l|l|l|}
\hline \multicolumn{1}{|c|}{ C3 (BEDS) } & \multicolumn{1}{|c|}{ CR = 0,0277 } & \multicolumn{3}{c|}{ C5 (EUROS/BEDS) } & \multicolumn{4}{c|}{ CR99 } \\
\hline & $\mathbf{2 5}$ & $\mathbf{2 0}$ & $\mathbf{1 0}$ & $\mathbf{7}$ & $\mathbf{4}$ & & $\mathbf{2 . 5 0 0}$ & $\mathbf{5 . 0 0 0}$ & $\mathbf{1 0 . 0 0 0}$ & $\mathbf{1 5 . 0 0 0}$ & $\mathbf{2 0 . 0 0 0}$ \\
\hline $\mathbf{2 5}$ & 1 & 1 & 3 & 7 & 9 & $\mathbf{2 . 5 0 0}$ & 1 & 3 & 5 & 7 & 8 \\
\hline $\mathbf{2 0}$ & 1 & 1 & 3 & 7 & 9 & $\mathbf{5 . 0 0 0}$ & $1 / 3$ & 1 & 4 & 6 & 7 \\
\hline $\mathbf{1 0}$ & $1 / 3$ & $1 / 3$ & 1 & 3 & 7 & $\mathbf{1 0 . 0 0 0}$ & $1 / 5$ & $1 / 4$ & 1 & 5 & 6 \\
\hline $\mathbf{7}$ & $1 / 7$ & $1 / 7$ & $1 / 3$ & 1 & 3 & $\mathbf{1 5 . 0 0 0}$ & $1 / 7$ & $1 / 6$ & $1 / 5$ & 1 & 2 \\
\hline $\mathbf{4}$ & $1 / 9$ & $1 / 9$ & $1 / 7$ & $1 / 3$ & 1 & $\mathbf{2 0 . 0 0 0}$ & $1 / 8$ & $1 / 7$ & $1 / 6$ & $1 / 2$ & 1 \\
\hline
\end{tabular}

\subsection{Prioritization of all evaluations by interpolation}

Considering the normalized evaluation of the reference evaluations obtained by the application of AHP (Table 9) and interpolating them as described in Section 2.2, we were able to obtain the normalized evaluations of the considered $\mathrm{SH}$ projects with respect to all criteria reported in Table 10 (phase 5 of the methodology summarized in Table 2).

Table 9. Reference evaluations for considered criteria and normalized values obtained by AHP

\begin{tabular}{|c|c|c|c|c|c|c|c|c|c|}
\hline C1 & Normalized & C2 & Normalized & C3 & Normalized & C4 & Normalized & C5 & Normalized \\
\hline 0 & 0 & 0 & 0 & 4 & 0 & 0 & 0 & 2.500 & 1 \\
\hline 5 & 0.2060 & 5 & 0.1165 & 7 & 0.0881 & 4 & 0.2505 & 5.000 & 0.5473 \\
\hline 8 & 0.6398 & 8 & 0.4929 & 10 & 0.3664 & 8 & 0.6941 & 10.000 & 0.2314 \\
\hline 10 & 1 & 10 & 0.8203 & 20 & 1 & 10 & 1 & 15.000 & 0.0317 \\
\hline- & - & 15 & 1 & 25 & 1 & - & - & 20.000 & 0 \\
\hline C6 & Normalized & $\mathbf{C 7}$ & Normalized & $\mathbf{C 8}$ & Normalized & $\mathbf{C 9}$ & Normalized & C10 & Normalized \\
\hline 0 & 0 & 0 & 0 & 0 & 0 & 0 & 0 & 0 & 0 \\
\hline 7 & 0.1807 & 5 & 0.1852 & 10 & 0.1111 & 5 & 0.1618 & 7 & 0.1202 \\
\hline 11 & 0.4630 & 7 & 0.1516 & 20 & 0.5591 & 7 & 0.6143 & 11 & 0.5347 \\
\hline 15 & 1 & 10 & 1 & 25 & 1 & 10 & 1 & 15 & 1 \\
\hline
\end{tabular}

For example, to obtain the normalized value of the $\mathrm{SH}$ project $\mathrm{P} 1$ with respect to the criterion $\mathrm{C} 5$ (Euros/Beds), first of all we observed that its evaluation (7,500 euro) is in the interval of the references 5,000 euro and 10,000 euro for C5. Since the normalized evaluations of the two reference evaluations obtained by AHP are respectively 0.5473 and 0.2314 , applying the equation (1) we get the normalized evaluation of $\mathrm{C} 5$ for the SH project P1 as follows: 


$$
u(7.500)=u(5,000)+\frac{u(10,000)-u(5,000)}{(10,000)-(5,000)}(7,500-5,000)=0.3894
$$

Table 10. Set of considered SH projects with normalized evaluations on each criterion

\begin{tabular}{|c|c|c|c|c|c|c|c|c|c|c|}
\hline \multirow{2}{*}{ ID } & \multicolumn{10}{|c|}{ DECISION CRITERIA } \\
\hline & C1 & C2 & C3 & C4 & C5 & C6 & C7 & C8 & C9 & C10 \\
\hline P1 & 0.8199 & 0.8922 & 1 & 1 & 0.3894 & 0.5973 & 0.4344 & 0.4695 & 0.7429 & 0.2238 \\
\hline $\mathbf{P 2}$ & 1 & 0 & 0.0587 & 0.3614 & 0.3293 & 0.3218 & 0.1684 & 0.2007 & 1 & 0.7674 \\
\hline P3 & 0.6398 & 0.8563 & 0.1809 & 0.6941 & 0.0190 & 0.3924 & 0.1684 & 0.3351 & 0.0647 & 1 \\
\hline P4 & 1 & 0.4929 & 1 & 1 & 0.9276 & 0.7315 & 0.4344 & 0.1111 & 0.7429 & 0.4311 \\
\hline P5 & 0.6398 & 0.2420 & 0.0587 & 0.6941 & 0.0158 & 0.3924 & 0.1684 & 0.5591 & 0.0647 & 0.0858 \\
\hline P6 & 0.2060 & 0.0233 & 0.1809 & 0.4723 & 0.2630 & 0.8658 & 1 & 1 & 0.7429 & 0.4311 \\
\hline P7 & 1 & 0.2420 & 0.0294 & 0.2505 & 0.8624 & 0.5973 & 0.4344 & 0.4247 & 0.6143 & 0.0858 \\
\hline P8 & 1 & 0.4929 & 0.3664 & 0.5832 & 0.3894 & 0.3924 & 0.1684 & 0.2007 & 0.0971 & 0.7674 \\
\hline P9 & 0.4952 & 0.0932 & 1 & 0.8470 & 0.5926 & 0.4630 & 0.4344 & 0.2455 & 0.0971 & 0.3274 \\
\hline P10 & 0.6398 & 0.4929 & 1 & 0.5832 & 0.4420 & 0.4630 & 1 & 0.3351 & 0 & 0.8837 \\
\hline P11 & 0.8199 & 0.4929 & 0.1809 & 0.6941 & 0.1632 & 1 & 0.7172 & 0.8236 & 0.1618 & 0.4311 \\
\hline P12 & 1 & 0.1165 & 0.1809 & 0.8470 & 0 & 0.0258 & 0.0741 & 0.0222 & 0 & 0.0687 \\
\hline P13 & 1 & 0.9281 & 0.6832 & 0.6941 & 0.3578 & 0.3218 & 0.1852 & 0.2903 & 1 & 0.5347 \\
\hline P14 & 1 & 0.0932 & 0.1809 & 0.5832 & 0.0317 & 0.1807 & 0.1684 & 0.2007 & 0.3880 & 0.1030 \\
\hline P15 & 0.6398 & 0.1165 & 0.0881 & 0.4723 & 0.3126 & 0.8658 & 0.4344 & 0.6473 & 0.0647 & 0.6510 \\
\hline P16 & 0.6398 & 0.8563 & 0.1809 & 0.8470 & 0.1315 & 0.1807 & 0.1684 & 0.3351 & 0 & 0.4311 \\
\hline P17 & 0.4952 & 0.0932 & 1 & 0.5832 & 0.5473 & 0.1549 & 0.1516 & 0.3351 & 0.3880 & 0.4311 \\
\hline P18 & 0.4952 & 0.0466 & 0 & 0.5832 & 0.0816 & 0.7315 & 1 & 0.7355 & 0 & 0.0172 \\
\hline P19 & 0.8199 & 0.9641 & 1 & 1 & 0.4237 & 0.3218 & 0.1852 & 0.2903 & 0.3880 & 0.1030 \\
\hline $\mathbf{P 2 0}$ & 0.6398 & 0.4929 & 1 & 0.4723 & 0.3825 & 0.1549 & 0.0741 & 0.2455 & 0.1618 & 0.2238 \\
\hline P21 & 0.2060 & 0.3674 & 0.6832 & 0.3614 & 0.7284 & 0.1549 & 0.1111 & 0.0556 & 0.0647 & 0.0515 \\
\hline
\end{tabular}

Figure 2 shows the normalized values for the whole scales of all the considered criteria. As one can observe, the AHP was necessary to put all reference evaluations on the same scale. Indeed, the ten subfigures show that the preferences provided by the DM are far from being linear. This underlines the importance of considering the element of subjectivity in the preferences and the sensitivity of the measure of the utility attributed from one threshold to another. One important remark in the context of choice architecture that guided our work is that in the preference information supplied by the DM there was no violation of the monotonicity between rating and prioritization. This was not the case in some experiments related to an abstract problem of evaluating the areas of geometric figures conducted with some students at the University of Catania and reported in Abastante et al. 2018. We interpret the consistency of preference information obtained in our real-world application as a positive aspect of our methodology that was able to attract the attention of DM who answered in a consistent way. 

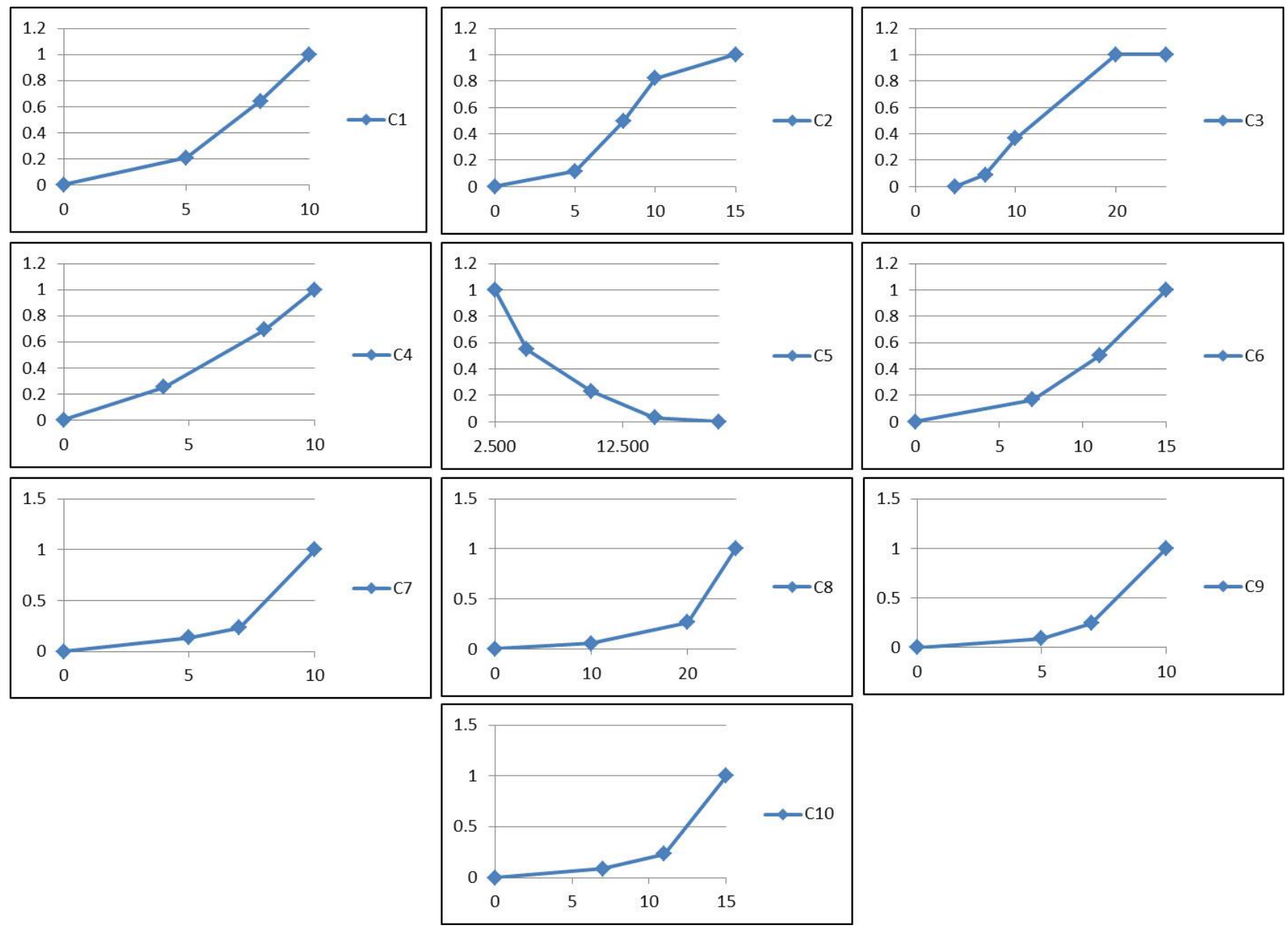

Figure 2. Normalized values for the reference evaluations obtained by AHP

\subsection{Definition of the interactions between the considered criteria}

To take into account the interaction between criteria, we aggregated the performances of alternatives at hand by means of the Choquet integral preference model. Therefore, considering the indirect preference information, a further meeting with the DM was needed. During this meeting the DM defined the preference information about the interaction between criteria (phase 6 of the methodology summarized in Table 2). The provided interactions are the following (with $\varepsilon$ denoting a small positive number, such that, for any quantity $x, x \geq \varepsilon$ stands for $x>0$ ): 
1. Human resources $(C 7)$ and Synergies $(C 10)$ are positively interacting ${ }^{4}(\varphi(C 7, C 10) \geq \varepsilon)$ : the $\mathrm{DM}$ affirmed that this interaction reflects the ability of the $\mathrm{SH}$ projects to activate synergies and networks with the human resources already operating on the territory. In this sense, the project reduces the economic costs of the human resources;

2. Clarity and innovation (C6) and Economic sustainability (C9) are positively interacting $(\varphi(C 6, C 9) \geq \varepsilon)$ : according to the DM suggestions, a well-structured and innovative $\mathrm{SH}$ project has the ability to attract private finances and it is therefore economically sustainable in a long-term period;

3. Beds (C3) and Euro/Beds (C5) are positively interacting $(\varphi(C 3, C 5) \geq \varepsilon)$ : the DM affirmed that a valuable $\mathrm{SH}$ project should contain the costs in terms of euro/beds but, at the same time, it should increase the number of beds provided;

4. Beds (C3) and Economic sustainability (C9) are positively interacting $(\varphi(C 3, C 9) \geq \varepsilon)$ : the logical consequence of projects having a low number of beds is the low income obtained from rents. As a matter of fact, a SH project is valuable for the DM if it can ensure an economic sustainability in long-term period even in such circumstances;

5. Human resources $(C 7)$ and Economic sustainability (C9) are positively interacting $(\varphi(C 7, C 9) \geq \varepsilon)$ : in general, the economic sustainability of the $\mathrm{SH}$ projects requires an intricate administration, which needs in turn a huge amount of human resources. The interaction here described reflects the ability of some $\mathrm{SH}$ projects of ensuring an economic sustainability in long-term period having few human resources;

6. Beds (C3) and Human resources $(C 7)$ are positively interacting $(\varphi(C 3, C 7) \geq \varepsilon)$ : the DM affirmed that this is a fundamental interaction because it contains the core of the $\mathrm{SH}$ concept; a sensible number of beds together with low human resources for the social activities means that the beneficiaries are autonomous as requested by the SH philosophy;

7. Overall consistency $(\mathrm{Cl})$ and Clarity and innovation (C6) are positively interacting $(\varphi(C 1, C 6) \geq \varepsilon)$ : following the DM reasoning, a clear and innovative SH project can only work if the location of the buildings, the internal/external spaces and the shared rooms are suitable to receive innovative social activities. Indeed, the SH projects are usually destined to people facing physical or psychological fragilities and requiring for specific social activities and spaces. In this sense, the $P H$ pays attention to the concrete correspondence among the technical features of the spaces and the expected social activities;

8. Beds $(C 3)$ and Economic consistency $(C 4)$ are positively interacting $(\varphi(C 3, C 4) \geq \varepsilon)$ : the DM affirmed that providing a huge amount of beds as well as containing the economic consistency of the SH projects is usually a difficult task. Therefore, they decided to attribute a bonus to the projects reaching this objective;

9. Clarity and innovation (C6) and Human resources (C7) are positively interacting $(\varphi(C 6, C 7)$ $\geq \varepsilon$ ): the DM expressed their interest in innovative $\mathrm{SH}$ projects having a low amount of human resources. Usually, if the social activities planned in a $\mathrm{SH}$ project are very innovative, they could host also heterogeneous beneficiaries as, for example, young couples and elderly people. This means that people who need for social support and people who don't, could help each other. In this sense, the human resources needed to manage the social activities are reduced and the related costs are cut down.

\footnotetext{
${ }^{4}$ Among parenthesis we inserted the constraints translating the corresponding piece of preference information
} 


\subsection{First rankings of decision criteria and SH projects}

During the same meeting, the DM were also asked to provide an order on the decision criteria in terms of their importance. After a long discussion, they decided to provide two different importance rankings according to the social and technical criteria. The importance rankings are the following:

- Importance ranking of social decision criteria: $\mathrm{C} 8>\mathrm{C} 7>\mathrm{C} 6>\mathrm{C} 9>\mathrm{C} 10$;

- Importance ranking of technical decision criteria: $\mathrm{C} 1>\mathrm{C} 4>\mathrm{C} 2>\mathrm{C} 5>\mathrm{C} 3$.

According to the interactions between criteria and to the rankings of social and technical criteria so far provided, we were able to present to the DM a first comprehensive ranking of the decision criteria according to their importance as measured by the Shapley value (phase 7 of the methodology summarized in Table 2) on the capacity obtained computing the most representative value function (Table 11).

Table 11. First importance ranking of the decision criteria

\begin{tabular}{|c|c|}
\hline CRITERIA RANKING & Shapley index \\
\hline Social tools and methodologies (C8) & 0.1809 \\
\hline Overall consistency (C1) & 0.1648 \\
\hline Economic consistency (C4) & 0.1451 \\
\hline Quality of the design project (C2) & 0.1253 \\
\hline Human resources (C7) & 0.1009 \\
\hline Clarity and innovation (C6) & 0.0812 \\
\hline Economic sustainability (C9) & 0.0615 \\
\hline Euros/beds (C5) & 0.0592 \\
\hline Synergies (C10) & 0.0417 \\
\hline Beds (C3) & 0.0395 \\
\hline
\end{tabular}

A first ranking of the alternative $\mathrm{SH}$ projects, obtained by the most representative value function (phase 7 of the methodology summarized in Table 2) has also been presented to the DM (Table 12).

Table 12. First ranking of the alternative SH projects

\begin{tabular}{|c|c|c|c|c|c|}
\hline POSITION & ID & Choquet Value & POSITION & ID & Choquet Value \\
\hline $\mathbf{1}^{\circ}$ & P11 & 0.5733 & $\mathbf{1 2}^{\circ}$ & P7 & 0.3115 \\
\hline $\mathbf{2}^{\circ}$ & P1 & 0.5311 & $\mathbf{1 3}^{\circ}$ & P8 & 0.3097 \\
\hline $\mathbf{3}^{\circ}$ & P19 & 0.4617 & $\mathbf{1 4}^{\circ}$ & P9 & 0.2849 \\
\hline $4^{\circ}$ & P10 & 0.4240 & $\mathbf{1 5}^{\circ}$ & P5 & 0.2643 \\
\hline $5^{\circ}$ & P13 & 0.4230 & $\mathbf{1 6}^{\circ}$ & P20 & 0.2513 \\
\hline $\mathbf{6}^{\circ}$ & P3 & 0.4152 & $\mathbf{1 7}^{\circ}$ & P17 & 0.2213 \\
\hline $7^{\circ}$ & P18 & 0.3955 & $\mathbf{1 8}^{\circ}$ & P2 & 0.2195 \\
\hline $\mathbf{8}^{\circ}$ & P16 & 0.3955 & $\mathbf{1 9}^{\circ}$ & P21 & 0.2120 \\
\hline $9^{\circ}$ & P6 & 0.3955 & $\mathbf{2 0}^{\circ}$ & P14 & 0.1679 \\
\hline $\mathbf{1 0}^{\circ}$ & P4 & 0.3955 & $\mathbf{2 1}^{\circ}$ & P12 & 0.1276 \\
\hline $\mathbf{1 1}^{\circ}$ & P15 & 0.3559 & & &
\end{tabular}


After seeing the two rankings (Table 11 and Table 12), the DM realized that it was very important to add some information to those already provided. The DM stated that, according to their knowledge about the SH projects, there were sensible differences among their thoughts and the provided rankings.

\subsection{Final rankings of decision criteria and SH projects}

In order to obtain an importance ranking of criteria and a preference ranking of alternatives more satisfactory for the DM, after our solicitation the DM provided the following further information:

- An overall ranking of the decision criteria expressed as follows:

$$
\mathrm{C} 8>\mathrm{C} 1>\mathrm{C} 7>\mathrm{C} 6>\mathrm{C} 4>\mathrm{C} 2>\mathrm{C} 9>\mathrm{C} 5>\mathrm{C} 10>\mathrm{C} 3 \text {; }
$$

- A ranking on some SH projects on which she had a clear opinion. After a long internal discussion, the DM arrived at the following partial ranking:

$$
\mathrm{P} 1>\mathrm{P} 4>\mathrm{P} 10>\mathrm{P} 19>\mathrm{P} 6>\mathrm{P} 11 .
$$

Moreover, the DM agreed on the fact that the $6 \mathrm{SH}$ projects above are preferred to the other 15 alternative projects.

Denoting by $P$ the set composed of all different $\mathrm{SH}$ projects, this preference information is translated into the following linear inequalities:

- $\quad C_{\mu}(\mathrm{P} 1) \geq C_{\mu}(\mathrm{P} 4)+\varepsilon$

- $\quad C_{\mu}(\mathrm{P} 10) \geq C_{\mu}(\mathrm{P} 19)+\varepsilon$

- $\quad C_{\mu}(\mathrm{P} 6) \geq C_{\mu}(\mathrm{P} 11)+\varepsilon$

- $C_{\mu}(\mathrm{P} 4) \geq C_{\mu}(\mathrm{P} 10)+\varepsilon$

- $C_{\mu}(\mathrm{P} 19) \geq C_{\mu}(\mathrm{P} 6)+\varepsilon$

- $\quad C_{\mu}(P 11) \geq C_{\mu}(P x)$ for all $P x \in P \backslash\{\mathrm{P} 1, \mathrm{P} 4, \mathrm{P} 6, \mathrm{P} 10, \mathrm{P} 11, \mathrm{P} 19\}$

Considering the preference information about the interaction between criteria together with the overall ranking of the decision criteria and the preferences over SH projects previously described, we were able to show the DM the following further results:

- A final importance ranking of the decision criteria as measured by the Shapley value (Table 13).

Table 13. Final importance ranking of the decision criteria

\begin{tabular}{|c|c|}
\hline CRITERIA RANKING & Shapley index \\
\hline Social tools and methodologies (C8) & 0.2050 \\
\hline Overall consistency (C1) & 0.1250 \\
\hline Human resources (C7) & 0.1200 \\
\hline Clarity and innovation (C6) & 0.1150 \\
\hline Economic consistency (C4) & 0.1100 \\
\hline
\end{tabular}




\begin{tabular}{|c|c|}
\hline Quality of the design project (C2) & 0.1050 \\
\hline Economic sustainability (C9) & 0.1000 \\
\hline Euros/beds (C5) & 0.0950 \\
\hline Synergies (C10) & 0.0150 \\
\hline Beds (C3) & 0.0100 \\
\hline
\end{tabular}

- A final ranking of the alternative SH projects according to the Choquet integral corresponding to the most representative value function of each project (Table 14).

Table 14. Final ranking of the alternative SH projects

\begin{tabular}{|c|c|c|c|c|c|}
\hline POSITION & ID & Choquet Value & POSITION & ID & Choquet Value \\
\hline $\mathbf{1}^{\circ}$ & P1 & 0.5516 & $\mathbf{1 2}^{\circ}$ & P9 & 0.3180 \\
\hline $\mathbf{2}^{\circ}$ & P4 & 0.5466 & $\mathbf{1 3}^{\circ}$ & P18 & 0.2999 \\
\hline $\mathbf{3}^{\circ}$ & P10 & 0.4543 & $\mathbf{1 4}^{\circ}$ & P15 & 0.2939 \\
\hline $4^{\circ}$ & P19 & 0.4493 & $\mathbf{1 5}^{\circ}$ & P2 & 0.2647 \\
\hline $5^{\circ}$ & P6 & 0.4443 & $\mathbf{1 6}^{\circ}$ & P17 & 0.2647 \\
\hline $\mathbf{6}^{\circ}$ & P11 & 0.4393 & $\mathbf{1 7}^{\circ}$ & P20 & 0.2647 \\
\hline $7^{\circ}$ & P13 & 0.4136 & $\mathbf{1 8}^{\circ}$ & P14 & 0.2613 \\
\hline $\mathbf{8}^{\circ}$ & P7 & 0.3887 & $\mathbf{1 9}^{\circ}$ & P5 & 0.2584 \\
\hline $9^{\circ}$ & P8 & 0.3821 & $\mathbf{2 0}^{\circ}$ & P12 & 0.2398 \\
\hline $\mathbf{1 0}^{\circ}$ & P3 & 0.3180 & $\mathbf{2 1}^{\circ}$ & P21 & 0.1692 \\
\hline $\mathbf{1 1}^{\circ}$ & P16 & 0.3180 & & &
\end{tabular}

\section{Discussion of the results}

It is worthwhile to comment the results obtained by comparing the first and final rankings of the decision criteria (Table 11 and Table 13) and the comprehensive evaluation of the alternative SH projects (Table 12 and Table 14). It is important to remind that the first rankings (Table 11 and 12) were based on the preference information about interactions between criteria and two distinct importance rankings of social and technical criteria, while the final rankings (Tables 13 and 14) were based on the interactions between criteria, the ranking of all criteria and the preference on some SH projects expressed by the DM.

With respect to the two importance rankings of decision criteria provided by the proposed methodological approach, we can observe that few differences emerged.

Table 15. Main differences between the first and the final decision criteria rankings

\begin{tabular}{|c|c|c||c|c|c|}
\hline \multicolumn{2}{|c||}{ FIRST DECISION CRITERIA RANKING } & \multicolumn{2}{c|}{ FINAL DECISION CRITERIA RANKING } \\
\hline Position & Criterion & Shapley index & Position & Criterion & Shapley index \\
\hline $\mathbf{1}^{\circ}$ & $\mathrm{C} 8$ & 0.1809 & $\mathbf{1}^{\circ}$ & $\mathrm{C} 8$ & 0.2050 \\
\hline $\mathbf{2}^{\circ}$ & $\mathrm{C} 1$ & 0.1648 & $\mathbf{2}^{\circ}$ & $\mathrm{C} 1$ & 0.1250 \\
\hline $\mathbf{3}^{\circ}$ & $\mathrm{C} 4$ & 0.1451 & $\mathbf{3}^{\circ}$ & $\mathrm{C} 7$ & 0.1200 \\
\hline
\end{tabular}

Looking at the first three positions of both rankings of decision criteria (Table 15), outwardly we can say that the only difference is related to the third position that is occupied by the criterion $\mathrm{C} 4$ (Economic consistency) in the first ranking and by the criterion C7 (Human resources) in the final 
one. However, it is important to highlight the differences in terms of Shapley index. Indeed, in considering the two different criteria rankings, criterion $\mathrm{C} 8$ is the most important one but its difference from the second $(\mathrm{C} 1)$ is lower than the difference between the same criteria in the final importance ranking of the criteria. In this second case, C8 is, without any doubt, the most important criterion while $\mathrm{C} 1$ and $\mathrm{C} 7$ are quite similar. In fact, according to the new information provided by the DM, the importance of the criterion C8 (Social tools and methodologies) with respect to the criterion $\mathrm{C} 1$ (Overall consistency) substantially increases in the final decision criteria ranking (the difference of Shapley index between C8 and C1 increased 4 times). Moreover, the Shapley index of the criterion $\mathrm{C} 7$ is almost equal to the Shapley index of the criterion $\mathrm{C} 1$.

It is interesting to notice that $\mathrm{C} 8$ is always considered the most important criterion even if it is never mentioned in the preference information about the interaction between criteria (Section 3.5) given by the DM. This means that the performance of the $\mathrm{SH}$ projects on $\mathrm{C} 8$ are fundamental for the assessment process.

With respect to the provided partial ranking of the alternative SH projects, substantial differences can be noticed (Table 16).

Table 16. Main differences between the first and the final alternative SH projects rankings

\begin{tabular}{|c|c|c||c|c|c|}
\hline \multicolumn{2}{|c||}{ FIRST ALTERNATIVE RANKING } & \multicolumn{3}{c|}{ FINAL ALTERNATIVE RANKING } \\
\hline POSITION & ID & Choquet Value & POSITION & ID & Choquet Value \\
\hline $\mathbf{1}^{\circ}$ & P11 & 0.5733 & $\mathbf{1}^{\circ}$ & P1 & 0.5516 \\
\hline $2^{\circ}$ & P1 & 0.5311 & $2^{\circ}$ & P4 & 0.5466 \\
\hline $3^{\circ}$ & P19 & 0.4617 & $3^{\circ}$ & P10 & 0.4543 \\
\hline
\end{tabular}

A change in the preference orders between the first and the final alternative rankings is immediately recognisable. In fact, the only project appearing in the two rankings is $\mathrm{P} 1$, which obtains the second position in the first ranking and the first position in the final one.

\subsection{First ranking analysis}

In order to better understand the meaningfulness of the first ranking results reported in Table 16, the projects P11, P1, P19 have been analysed according to:

- the performance of each project (Table 10) with respect to the criteria C8, C1 and C4 (resulting as the most important ones in the first decision criteria ranking);

- the interaction between criteria given by the DM and involving the three aforementioned criteria.

The project P11 (with a Choquet integral value of 0.5733 ) shows very good performances on criterion C8 (0.8236) and C1 (0.8199) and good performances on criterion C4 (0.6941). Moreover, as stated by the DM, C1 and C6 are positively interacting and the performances of P11 on these two criteria are excellent (0.8199 and 1, respectively). In line with this analysis, it seems therefore justified to see P11 in the first position of the first ranking.

The project P1 (with a Choquet integral value of 0.5311 ) has low performances on criterion C8 (0.4695) but very good performances on C1 (0.8199) and excellent on C4 (1). Because of the 
positive interaction between $\mathrm{C} 3$ and $\mathrm{C} 4$ stated from the $\mathrm{DM}$ and the good performances of $\mathrm{P} 1$ on these two criteria (both of them equal to 1), its second position can be partly justified by the low performance on $\mathrm{C} 8$.

Analogously, the project P19 (with a Choquet integral value of 0.4617 ) has very low performances on C8 (0.2903). This permits it to attain the third position of the first ranking. In fact, the performances of this project on criteria $\mathrm{C} 1$ and $\mathrm{C} 4$ are identical to those of project $\mathrm{P} 1$.

\subsection{Final ranking analysis}

In the same way, we explored the final ranking results reported in Table 16. The projects P1, P4 and P10 have been analysed according to:

- the performance of each project (Table 10) with respect to criteria $\mathrm{C} 8, \mathrm{C} 1$ and $\mathrm{C} 7$ (resulting as the most important ones in the final decision criteria ranking);

- the interaction between criteria given by the DM and involving the three aforementioned criteria.

The performances of the project P1 (with a Choquet integral value of 0.5516) with respect to criteria $\mathrm{C} 8$ and $\mathrm{C} 1$ are identical to the ones mentioned for the first ranking. The performances of this project on criterion C7 (0.4344) are very low. However, due to positive interactions of C7 with the criteria C3, C6 and C9 expressed by the DM, the project P1 gets the first position of the final ranking. It is important to highlight that this project has been also specified as the most preferred one by the DM in the preference order on the set of SH projects that they were informed about. The project P4 (with a Choquet integral value of 0.5466 ) shows very low performance on C8 (0.1111) while that one on $\mathrm{C} 1$ is excellent (1). Moreover, the positive interaction between $\mathrm{C} 1$ and C6 and its good performances on these two criteria (1 and 0.7315) give an added value to this project. It is important to notice that the overall performances of P1 and P4 are very similar in terms of the Choquet integral values. In case of $\mathrm{P} 4$, the preference information expressed in terms of ranking of some SH projects turned out to be fundamental for the position of this project in the final ranking. In fact, if we do not consider this information, the project P4 would result better than P1 according to the other information.

The project P10 (with a Choquet integral value of 0.4543 ) has low performances on C8 (0.3351), very good performances on $\mathrm{C} 1$ (0.6398) and excellent performances on C7 (1).

Starting from the analysis of the first and the final rankings it is possible to provide general reflections. First, criterion C8 (Social tools and methodologies) is confirmed to be the most important because of its intrinsic nature. In fact, even if it does not show interactions with other criteria, good performances on criterion $\mathrm{C} 8$ are fundamental for a $\mathrm{SH}$ project to reach the top of the ranking. This is in line with the actual selection process adopted by the DM for which criterion $\mathrm{C} 8$ can contribute with a very high maximum score to the comprehensive evaluation of $\mathrm{SH}$ projects (Table 5). Moreover, this reflection agrees with the SH basic idea considering the social tools and activities indispensable for the $\mathrm{SH}$ projects.

Second, criterion C7 (Human resources) showed to be fundamental in the second ranking due to its numerous interactions with other criteria, which are able to support the performances of $\mathrm{C} 7$.

Finally, the emerged differences between the first and the final rankings highlight the importance of the information provided by the DM. In fact, the final rankings are based on different and more accurate information with particular reference to the preference order on some SH projects stated by 
the DM. In this sense, the further information acquired for the final ranking has been fundamental to come to sensible and interesting results for the DM.

\section{Conclusions}

In this paper, we structure a decision process related to architecture choices advocating the concept of choice architecture. We use therefore a very meaningful "word pun": choice architecture for architecture choices.

The idea is that the decision procedure has to take into account bounded rationality and cognitive biases of decision makers (Miller 1956, Hammond et al. 1999, Milkman et al. 2009). In the specific $\mathrm{SH}$ realm, the challenge is multidimensional and requires a multidisciplinary approach: the buildings must have low construction and operation costs, they have to be sustainable from an economic, energy and social point of view, the services that they offer have to take into account the needs of the inhabitants and they should be easily usable. Technology alone does not guarantee low energy performance in buildings, since a lot depends on the occupants' actions and their ability to interact with control systems. In addition to the cost optimal levels (the link between energy cost, energy rating and building property value), the DM has also to consider how to ensure a sufficient level of profitability for a social operation attracting private investments and how to evaluate (both qualitatively and quantitatively) the services that accompany the intervention, defining the most appropriate ones for the urban context and the target audience at stake.

In order to help the DM to handle all this information, and assuming that choice architecture interventions can influence individual behaviour, we proposed the application of a new Multicriteria Decision Aiding methodology putting together the "Parsimonious AHP" (an extension of AHP to deal with a huge number of alternatives), the Choquet integral and the Robust Ordinal Regression (used to take into consideration interaction between criteria and imprecise elicitation of the preference parameters). The new method was applied in a complex socioeconomic problem that is the evaluation of alternative SH projects sited in the Piedmont region (Italy). The application reflects one of the two typical situations in SH realm: a portfolio problem, where many proposals have to be evaluated in the presence of a limited budget and only one of these, or at most few, can be selected. The second is structuring a tender and choosing the winner, where there is a specific location and one transformation has to be selected from among the different proposals. The application of the method to the case study showed three remarkable contributions to the decision process, assuming the bounded rationality of the DM: i) collection of preference information from the DM in an easy and understandable way; ii) consideration of complex aspects of the decision problems (in our case, interaction between criteria) but taking the whole methodology as simple as possible; iii) limited number of pairwise comparisons asked to the DM.

Due to privacy concern, we cannot compare the final ranking obtained by the application here presented with the real one, but some general observation given directly by the DM can be reported. The decision support procedure illustrated in this paper involved different interactions with the DM and showed how the proposed method can help to have a better understanding of the problem at hand. The methodology proved to be useful in stimulating the discussion with the stakeholders; re-thinking about the decision criteria; and re -thinking about the reference levels.

The procedure conjugates the advantages of AHP in building a measurement scale and the advantages of the Choquet integral in handling interaction between criteria. In this context, the 
adoption of NAROR seems very beneficial because it permits to avoid focusing on only one capacity (vectors of weights for interacting criteria), which can be misleading for the reliability of the final decision. This is particularly important in SH projects, as the homes for people in a social need are not simply a product (i.e. a building as a place to live), but above all a process (i.e. a series of operations intended to provide services to users not only related to health and comfort).

The methodology is effective and can be applied to different areas for tackling decision problems presenting a high number of alternatives or criteria, without asking a huge and unrealistic cognitive effort to the DM, but, however, without neglecting any important aspect of the problem, even the most complex and troublesome ones such as the interaction of considered criteria. The approach permits to organize the information by alternating stages of dialogue and calculation. The dialogue stages aim at collecting information directly from the DM, which can reveal their preferences about the alternatives and the criteria at stake. The DM preferences are in turn taken into account in the calculation stages.

Summarizing, we would like to point out the following remarks:

1) the choice architecture approach was very useful in designing the decision procedure and it gave very interesting results from the point of view of the quality of the whole decision process;

2) there is a need to design more effective Multicriteria methodologies through the adoption of choice architecture principles that permit to improve the whole decision process, permitting to get more transparent recommendations that the DM could better understand and accept.

In our opinion, the two above remarks constitute good reasons to pursue research on choice architecture applied to decision support of complex problems and, in this regard, we envisage the following possible objectives:

- defining systematically main theoretical basis of choice architecture for decision support, with a special focus on multiple criteria decision aiding,

- producing a testing in real world problems of a certain number of decision support procedures based on choice architectures,

- developing a critical discussion on theory and practice of choice architecture for decision support.

\section{Acknowledgments}

We would like to show our deep gratitude to:

- the Programma Housing team who provided insight and expertise that greatly assisted the research, although they may not agree with all of the interpretations/conclusions of this paper;

- Alessandro Armando (Politecnico di Torino) who provided the graphical abstract;

- Salvatore Corrente e Salvatore Greco wish to acknowledge the funding by the "FIR of the University of Catania BCAEA3, New developments in Multiple Criteria Decision Aiding (MCDA) and their application to territorial competitiveness" and of the research project "Data analytics for entrepreneurial ecosystems, sustainable development and wellbeing indices" of the Department of Economics and Business of the University of Catania. Salvatore Greco has also benefited of the fund "Chance" of the University of Catania.

\section{References}


Abastante, F. 2016. Multicriteria decision methodologies supporting decision processes: empirical examples. Geoingegneria ambientale mineraria 149, 5-18.

Abastante, F., Corrente, S., Greco, S., Ishizaka, A., Lami, I.M. 2018. A new parsimonious AHP methodology. Submitted. https://arxiv.org/ftp/arxiv/papers/1704/1704.08119.pdf

Abastante, F., Lami, I.M. 2013. An analytical model to evaluate a large scale urban design competition. GEAM. Geoingegneria ambientale mineraria 139, 27-36.

Allen, J., Barlow J., Leal J., Maloutas, T., Padovani, L. 2008. Housing and welfare in southern Europe. Blackwell publishing.

Angilella, S., Greco, S., Matarazzo, B. 2010a. Non-additive robust ordinal regression: a multiple criteria decision model based on the Choquet integral. European Journal of Operational Research 201(1), 277-288.

Angilella, S., Greco, S., Matarazzo, B. 2010b. The most representative utility function for non-additive robust ordinal regression. In: Hullermeier, E., Kruse, R., Hoffmann, F., eds. Proceedings of IPMU 2010, LNAI 6178. Heidelberg: Springer; 220-229.

Aragonés-Beltrán, P.A., Chaparro-González, F., Pastor-Ferrando, J.P.P., Rodríguez-Pozo, F. 2010. An ANPbased approach for the selection of photovoltaic solar power plant investment projects. Renewable and sustainable energy reviews 14 (1), 249-264.

Belton, V., Gear, T. 1983. On a short-coming of Saaty's method of analytic hierarchies. Omega 11(3), 228230.

Benítez, J., Delgado-Galván, X., Izquierdo, J., Pérez-García, R. 2012. An approach to AHP decision in a dynamic context. Decision Support Systems 53(3), 499-506.

Bottero, M., Lami, I.M. 2010. Analytic Network Process and Sustainable Mobility: an Application for the Assessment of Different Scenarios. Journal of Urbanism 3, 275-293.

Bozóki, S., Fülöp, J., Rónyai, L. 2010. On optimal completion of incomplete pairwise comparison matrices. Mathematical and Computer Modelling 52(1), 318-333.

Camerer, C., Loewenstein, G., Rabin, M. (Eds) 2004. Advances in behavioral economics. Princeton, NJ: Princeton University Press.

Camoletto, M., Ferri, G., Pedercini, C., Ingaramo, L., Sabatino, S. (2017). Social Housing and measurement of social impacts: step towards a common toolkit. Valori e Valutazioni 19, 11-39.

Campeol, G., Carollo, C., Masotto, N. 2016. Infrastructural Projects and Territorial Development in Veneto Dolomites: Evaluation of Performances through AHP. Procedia - Social and Behavioral Sciences, Volume 223, 10 June 2016, Pages 468-474.

Cay, T., Uyan, M. 2013. Evaluation of reallocation criteria in land consolidation studies using the Analytic Hierarchy Process (AHP). Land Use Policy 30, 541- 548.

Chen, K., Kou, G., Tarn, J.M., Song, Y. 2015. Bridging the gap between missing and inconsistent values in eliciting preference from pairwise comparison matrices. Annals of Operations Research 235(1), 155-175.

Choquet, G. 1953. Theory of capacities. Annales de l'institut Fourier 5, 131-295.

Corrente, S., Greco, S., Ishizaka, A. 2016. Combining analytical hierarchy process and Choquet integral within non-additive robust ordinal regression. Omega 61, 2-18.

Corrente, S., Greco, S., Kadziński, M., Słowiński, R. 2013. Robust ordinal regression in preference learning and ranking. Machine Learning 93, 381-422.

Crook, T., Kemp, P.A. 2014. Private Rental Housing. Cheltenham: Edward Elgar.

Csató, L., Rónyai, L. 2016. Incomplete pairwise comparison matrices and weighting methods. Fundamenta Informaticae 144(3-4), 309-320.

Czischke, D., Pittini, A. 2007 CECODHAS Housing Europe. Housing Europe 2007: Review of social, cooperative and public housing in the 27 EU member states. CECODHAS. 
Dartford Borough Council 2011. Vulnerable Adults' Housing Policy. Technical Report Available online: www.dartford.gov.uk/_data/assets/pdf_file/0013/10246/VAdultHousingpolicy.pdf (accessed on 04 June 2018).

Fedrizzi, M., Giove, S. 2007. Incomplete pairwise comparison and consistency optimization. European Journal of Operational Research 183(1), 303-313.

Gigerenzer, G., Goldstein, D.G. 1996. Reasoning the fast and frugal way: models of bounded rationality. Psychological review 103(4), 650-669.

Gigerenzer, G., Selten, R. 2012. Bounded rationality: The adaptive toolbox. MIT press.

Gomez-Ruiz, J.A., Karanik, M., Peláez, J.I. 2010. Estimation of missing judgments in AHP pairwise matrices using a neural network-based model. Applied Mathematics and Computation 216(10), 2959-2975.

Grabisch, M. 1996. The application of fuzzy integrals in multicriteria decision making. European Journal of Operational Research 89, 445-456.

Grabisch, M. 1997. k-order additive discrete fuzzy measures and their representation. Fuzzy Sets and Systems 92(2), 167-189.

Greco, S., Mousseau, V., Słowiński, R. 2008. Ordinal regression revisited: multiple criteria ranking using a set of additive value functions. European Journal of Operational Research 191(2), 416-436.

Haffner, M., Heylen, K. 2011. User Costs and Housing Expenses. Towards a more Comprehensive Approach to Affordability. Housing Studies 26(4), 593-614.

Hammond, J.S., Keeney, R.L., Raiffa, H. 1999. Smart choices. Harvard Business School PressBoston, MA.

Harker, P.T. 1987. Shortening the comparison process in the AHP. Mathematical Modelling 8, 139-141.

Häubl, G., Trifts, V. 2000. Consumer decision making in online shopping environments: the effects of interactive decision aids. Marketing Science 19, 4-21.

Housing Statistics: ec.europa.eu/eurostat/statistics-explained/index.php/Housing_statistics (accessed on 4 June 2018)

Ishizaka, A. 2012. Clusters and pivots for evaluating a large number of alternatives in AHP. Pesquisa Operacional 32(1), 87-102.

Ishizaka, A., Labib, A. 2011. Review of the main developments in the analytic hierarchy process. Expert Systems with Applications 38(11), 14336-14345.

Johnson, E.J., Shu, S.B., Dellaert, B.G., Fox, C., Goldstein, D.G., Häubl, G., Larrick, R.P., Payne, J.W., Peters, E., Schkade, D. and Wansink, B. 2012. Beyond nudges: Tools of a choice architecture. Marketing Letters 23(2), 487-504.

Kahneman, D. 2011. Thinking, fast and slow. Macmillan.

Kahneman, D. 2012. Foreword. In E. Shafir (Ed.), The behavioral foundations of public policy (pp. VII-IX). Princeton, NJ: Princeton University Press.

Keeney, R.L., Raiffa, H. 1976 Decisions with multiple objectives: preferences and value tradeoffs. New York, Wiley.

Lami, I.M. 2014. Analytical decision-making methods for evaluating sustainable transport in European Corridors. SxI - Springer for Innovation / SxI - Springer per l'Innovazione, vol. 11. Springer International Publishing, Cham.

Lami I.M. 2019. The Context of Urban Renewals as a 'Super-Wicked' Problem. In: Calabrò F., Della Spina L., Bevilacqua C. (Eds.) New Metropolitan Perspectives. ISHT 2018. Smart Innovation, Systems and Technologies, vol 100. Springer, Cham.

Lami, I.M., Abastante, F. 2014. Decision making for urban solid waste treatment in the context of territorial conflict: Can the Analytic Network Process help? Land Use Policy 41, 11-20.

Lami, I.M., Abastante, F. 2017. Social Housing evaluation procedures: literature review and step forward. Geoingegneria ambientale mineraria 150 (1), 15-28. 
Lami, I.M., Abastante, F., Bottero, M., Masala, E., Pensa, S. 2014. A MCDA and data visualization framework as a Problem Structuring Method (PSM) to address transport projects. In: Euro Journal of Decision Processes (EJDP), Special Issue on problem structuring, 2(3-4), 281-312.

Maleki. H., Zahir, S. 2013. A comprehensive literature review of the rank reversal phenomenon in the analytic hierarchy process. Journal of Multi-Criteria Decision Analysis 20(3-4), 141-155.

Marichal, J.L., Roubens, M. 2000. Determination of weights of interacting criteria from a reference set. European Journal of Operational Research 124(3), 641-650.

Marx, I., Nolan, B. 2012. In-Work Poverty. AIAS, GINI Discussion Paper; 51 ( the paper can be downloaded from the website www.gini-research.org).

Milkman, K.L., Chugh, D., Bazerman, M.H. 2009. How can decision making be improved? Perspectives on psychological science 4(4), 379-383.

Miller, G.A. 1956. The magical number seven, plus or minus two: some limits on our capacity for processing information. Psychological review 63(2), 81-97.

Munda, G. 2008. Social multi-criteria evaluation for a sustainable economy, Springer, Berlin.

Münscher, R., Vetter, M., Scheuerle, T. 2016. A Review and Taxonomy of Choice Architecture Techniques. Journal of Behavioural Decision Making, J. Behav. Dec. Making 29, 511-524.

Murofushi, S., Soneda, T. 1993. Techniques for reading fuzzy measures (III): interaction index. In: 9th Fuzzy Systems Symposium, Sapporo, Japan. 693-696.

Murray, K.B., Liang, J., Häubl, G. 2010. ACT 2.0: the next generation of assistive consumer technology research. Internet Research 20, 232-254.

Oxley, M. 2012. Supply-side subsidies for affordable rental housing. In: Smith S.J. (Ed.). International Encyclopaedia of Housing and home. Oxford: Elsevier Science.

Pensa, S., Masala, E., Lami, I.M. 2013. Supporting planning processes by the use of dynamic visualization. In: Geertman, S., Toppen, F., Stillwell, J. (Eds.), Planning Support Systems for Sustainable Urban Development. Springer, Heidelberg, Berlin, 451-467.

Pensa, S., Masala, E., Lami, I.M., Rosa, A. 2014. Seeing is knowing: data exploration as a support to planning. Proceedings of the institution of Civil Engineers. Civil Engineering 167, ISSN: 0965-089x, DOI: 10.1680/Cien.13.00017.

Petrini, M.A., Vieira Rocha, J., Brown, J.C., Bispo, R.C. 2016. Using an analytic hierarchy process approach to prioritize public policies addressing family farming in Brazil. Land Use Policy 51, 85-94.

Rota, G.C. 1964. On the foundations of combinatorial theory I. Theory of Möbius functions. Wahrscheinlichkeitstheorie und Verwandte Gebiete, 340-368.

Qureshi, M.E., Harrison, S.R. 2016. Comparing Riparian Revegetation Policy Options using the Analitic Hierarchy Process, in Herath, G. and Prato, T. (Eds.). Using Multi-Criteria Decision Analysis in Natural Resource Management, Routledge, New York.

Rezaei, J. 2015. Best-worst multi-criteria decision-making method. Omega 53, 49-57.

Roy, B.Słowiński, R. 2013. "Questions Guiding the Choice of a Multicriteria Decision Aiding Method." EURO Journal on Decision Processes 1, 69-97.

Saaty, T. 1977. A scaling method for priorities in hierarchical structures. Journal of Mathematical Psychology 15(3), 234-281.

Saaty, T. 1980. The analytic hierarchy process. New York: MacGraw-Hill.

Saaty, T. 1990. How to make a decision: the analytic hierarchy process. European Journal of Operational Research 48(1), 9-26.

Saaty, T., Ozdemir, M.S., 2003. Why the magic number seven plus or minus two. Mathematical and Computer Modelling 38(3-4), 233-244. 
Salgado, P., Quintana, C.S., Pereira, A.G., del Moral Ituarte, L., Mateos, B.P. 2009. Participative multicriteria analysis for the evaluation of water governance alternatives: a case in the Costa del Sol (Málaga). Ecological Economics 68, 990-1005.

Shapley, L.S. 1953. A value for $n$-person games. In: Kuhn, H.W., Tucker, A.W. Eds. Contributions to the theory of games II. Princeton: Princeton University Press, 307-317.

Shafir, E., (Ed.) 2012. The behavioural foundations of public policy. Princeton University Press.

Simon, H.A. 1955. A behavioural model of rational choice. The quarterly journal of economics 69(1), 99118.

Sklenicka, P. 2006. Applying evaluation criteria for the land consolidation effect to three contrasting study areas in the Czech Republic. Land Use Policy 23(4), 502-510.

Thaler R., Sunstein, C. 2008. Nudge: Improving Decisions About Health, Wealth, and Happiness. New Haven: Yale University Press.

Thaler, R.H., Sunstein, C. R., Balz, J.P. 2010. Choice architecture (SSRN Working Paper Series No. 1583509). Retrieved from the Social Science Research Network website: http://ssrn. com/abstract=1583509

Thapa, R.B., Murayama, Y. 2008. Land evaluation for peri-urban agriculture using analytical hierarchical process and geographic information system techniques: a case study of Hanoi. Land Use Policy 25, 225-239.

Tversky, A., Kahneman, D. 1974. Judgment under uncertainty: Heuristics and biases. Science 185, 11241131.

Wason, P.C. 1968. Reasoning about a rule. The Quarterly Journal of Experimental Psychology 20(3), 273281.

Whitehead, C., Monk, S., Scanlon, K., Markkanen, S., Tang, C. 2012. The Private Rented Sector in the New Century-A Comparative Approach. Cambridge: Cambridge Centre for Housing and Planning Research, $27-38$

Wills, J., Linneker, B. 2014. In-work poverty and the living wage in the United Kingdom: a geographical perspective. Transactions of the Institute of British Geographers 39(2), 182-194.

Wong, T.C., Goldblum, C. 2016. Social housing in France: A permanent and multifaceted challenge for public policies. Land Use Policy 54, 95-102. 